\title{
QUIMIOTERAPIA DA DOENÇA DE CHAGAS: ESTADO DA ARTE E PERSPECTIVAS NO DESENVOLVIMENTO DE NOVOS FÁRMACOS
}

\author{
Luiz C. Dias e Marco A. Dessoy \\ Departamento de Química Orgânica, Instituto de Química, Universidade Estadual de Campinas, Cidade Universitária Zeferino \\ Vaz, CP 6154, 13083-970 Campinas - SP, Brasil \\ Jean Jerley N. Silva, Otavio H. Thiemann, Glaucius Oliva e Adriano D. Andricopulo* \\ Instituto de Física de São Carlos, Universidade de São Paulo, CP 780, 13560-970 São Carlos - SP, Brasil
}

Recebido em 17/6/09; aceito em 2/9/09; publicado na web em 10/11/09

\begin{abstract}
CHEMOTHERAPY OF CHAGAS' DISEASE: STATE OF THE ART AND PERSPECTIVES FOR THE DEVELOPMENT OF NEW DRUGS. Neglected diseases are a major global cause of illness, long-term disability and death. Chagas' disease is a parasitic infection widely distributed throughout Latin America, with devastating consequences in terms of human morbidity and mortality. The existing drug therapy suffers from a combination of drawbacks including poor efficacy, resistance and serious side effects. In 2009, we celebrate the $100^{\text {th }}$ anniversary of the discovery of Chagas' disease, facing the challenges of developing new, safe and effective drugs for the treatment of this disease. This brief review attempts to highlight the state of the art, limitations and perspectives of Chagas' disease drug development.
\end{abstract}

Keywords: Chagas' disease; enzymes; inhibitors.

\section{INTRODUÇÃO}

As doenças infecciosas parasitárias afetam milhões de pessoas nas diferentes regiões geográficas mais pobres do planeta e representam uma crescente ameaça mundial. A malária, doença de Chagas, tripanossomíase africana (doença do sono), leishmaniose e esquistossomose são responsáveis por incapacitar anualmente uma fração significativa da população de vários países em desenvolvimento, especialmente do continente africano. ${ }^{1}$ A Organização Mundial de Saúde (OMS) expressa esse panorama pelo indicador chamado de anos de vida perdidos ajustados por incapacidade (DALY - disabilityadjusted life years), que é uma medida dos anos de vida saudáveis perdidos por um indivíduo que contraiu uma doença (morbidade e mortalidade). Para um estado de doença fatal ou grave condição de saúde, o DALY é estimado como os anos de vida perdidos devidos à morte prematura (YLL - years of life lost) somados aos anos vividos com incapacidade (YLD - years lived with disability), permitindo uma visão mais abrangente do impacto da doença.

As doenças parasitárias continuam sendo um obstáculo para o desenvolvimento social e econômico dos países mais pobres, e são frequentemente chamadas de "doenças negligenciadas", "doenças órfãs" ou "doenças tropicais". ${ }^{2}$ A maioria absoluta das mortes devido às doenças parasitárias ocorre em regiões situadas abaixo da linha do Equador. ${ }^{1}$ A necessidade de novas alternativas terapêuticas é clara, mas os investimentos globais em pesquisa e desenvolvimento (P\&D) de fármacos e vacinas são extremamente insuficientes. ${ }^{1,2}$

A doença de Chagas, descoberta em 1909 pelo médico brasileiro Carlos Chagas, é um dos principais problemas socioeconômicos enfrentados na América Latina. Esta doença, causada pelo protozoário parasita Trypanosoma cruzi, afeta cerca de 18 milhões de pessoas do sul dos Estados Unidos até a Patagônia, causando aproximadamente 50.000 mortes por ano, sendo que outros 100 milhões de indivíduos vivem em áreas de risco de contaminação. ${ }^{3,4}$ São estimados 700 mil DALYs e aproximadamente 300 mil novos casos por ano. ${ }^{1,2}$

Neste ano de 2009 são celebrados os 100 anos da descoberta da doença de Chagas. Em seu brilhante trabalho, Carlos Chagas identi-

\footnotetext{
*e-mail: aandrico@ifsc.usp.br
}

ficou não somente o agente etiológico, mas também o vetor e o modo de transmissão da doença, o que é considerado um feito extraordinário e único na história da medicina. Contudo, este momento especial e justo de comemorações do centenário da descoberta da doença nos proporciona a oportunidade de refletir sobre a urgência de novos medicamentos, já que não há qualquer tratamento eficaz para essa grave enfermidade. Portanto, faz-se necessário o fortalecimento de programas de pesquisas que visem o desenvolvimento de novos fármacos, promovendo ações de integração social, científica e tecnológica. Neste breve artigo de revisão, serão abordados o estado da arte, as limitações e perspectivas para o desenvolvimento de novos fármacos para a doença de Chagas, com ênfase em estratégias envolvendo aspectos fundamentais em química e biologia.

\section{DOENÇA DE CHAGAS}

\section{Aspectos biológicos}

O protozoário flagelado T. cruzi da ordem Kinetoplastida, família Trypanosomatidae e gênero Trypanosoma é o agente causador da doença de Chagas. ${ }^{5-7} \mathrm{O}$ parasita possui um complexo ciclo biológico, o qual envolve um hospedeiro invertebrado e outro vertebrado, e apresenta três formas distintas: (i) epimastigota, forma presente no vetor e em cultura axênica; (ii) tripomastigota, forma sanguínea circulante e infectante; e (iii) amastigota, forma de replicação intracelular. ${ }^{6,7}$

A infecção chagásica humana é caracterizada por uma fase aguda que dura em média 2 meses, sendo sucedida por uma fase crônica que tipicamente se prolonga por toda a vida do hospedeiro. Na maioria dos casos, a fase aguda da doença é oligossintomática, principalmente em adultos, não sendo valorizada pelo paciente ou pelo agente de saúde. Pode ainda não haver instalação de uma fase aguda clássica, uma vez que está relacionada diretamente com o número de parasitas inoculados. Quando esta se manifesta, apresenta um quadro febril ou outras manifestações clínicas, tais como miocardite, alterações eletrocardiográficas, linfadenopatia e hepatoesplenomegalia. ${ }^{7,8} \mathrm{~A}$ fase aguda sintomática ocorre principalmente em crianças, na primeira década de vida, podendo levar à morte devido a complicações decorrentes de insuficiência cardíaca e processos inflamatórios que envolvem o cére- 
bro (e.g., meningoencefalite). À medida que os níveis de parasitemia e as lesões inflamatórias da fase aguda diminuem em intensidade, uma miocardite focal se instala durante a fase indeterminada da doença, podendo em muitos casos evoluir em magnitude e abrangência, com a destruição de fibras cardíacas e aumento da fibrose. ${ }^{9,10}$ Cerca de $60 \%$ dos pacientes chagásicos crônicos permanecem assintomáticos por longo período, sendo que $30 \%$ destes desenvolvem complicações cardíacas que podem levar à cardiopatia chagásica crônica, lesão mais grave da doença, e/ou afetar o sistema gastrointestinal, resultando em severos problemas digestivos. ${ }^{8,9}$

Nas últimas décadas, evidências experimentais suportam duas hipóteses sobre a patogênese da cardiopatia chagásica crônica. $\mathrm{Na}$ primeira, a infecção pelo T. cruzi induz respostas imunológicas contra constituintes tissulares normais, que seriam parcialmente independentes da presença parasitária (teoria da autoimunidade na doença de Chagas). ${ }^{11,12} \mathrm{Na}$ outra hipótese, o parasitismo tissular persistente seria diretamente responsável pelas reações inflamatórias, acarretando em dano miocárdico irreversível. ${ }^{12,13}$ A cardiopatia chagásica crônica é a forma mais comum de doença miocárdica de etiologia não-isquêmica. ${ }^{14-18}$

A doença de Chagas é considerada um problema relevante de saúde pública em vários países da América Latina e, mais recentemente, também no sul dos Estados Unidos, levando a complicações socioeconômicas de grande extensão e complexidade. Embora muitos esforços no controle da transmissão vetorial tenham sido bem sucedidos, os resultados destas medidas não beneficiam diretamente os milhões de indivíduos infectados, nem tampouco os pacientes chagásicos com manifestações clínicas da doença. ${ }^{16,19}$

\section{Quimioterapia da doença de Chagas: um século de desafios, avanços e limitações}

A longa história da quimioterapia da doença de Chagas pode ser dividida em três fases principais. ${ }^{17-20}$ A primeira compreende o estágio inicial da descoberta da doença, de 1909 até 1935, e é marcada pela morte de Carlos Chagas (em novembro de 1934) e pelo lançamento do "Manual de Doenças Tropicais e Infectuosas" (em 1935), escrito por Carlos Chagas em coautoria com seu filho Evandro Chagas. ${ }^{17} \mathrm{~A}$ segunda fase, no período de 1936 a 1960, corresponde à avaliação biológica de inúmeras substâncias químicas, extratos e misturas de componentes, sendo marcada por resultados controversos e de significado clínico questionável. ${ }^{17,18}$ A última fase (a partir de 1961) é caracterizada por estudos que demonstraram claramente, através de modelos experimentais de infecção com T. cruzi em camundongos, a eficácia de alguns compostos como, por exemplo, a nitrofurazona (1) (Figura 1). ${ }^{20,21}$

Até o fim da primeira fase apenas dois trabalhos haviam sido publicados sobre a terapêutica experimental da doença de Chagas. Em ambos, os resultados foram insatisfatórios. Na segunda fase, foram descritos resultados de mais de 20 quimioterápicos e 30 antibióticos, dentre os quais se destacam algumas substâncias que tiveram efeito supressivo sobre a infecção causada pelo T. cruzi. ${ }^{18-20}$ Entre os agentes empregados nesta fase, destaca-se o antisséptico violeta de genciana (2) (Figura 1), que ainda hoje é utilizado como agente profilático em bancos de sangue.

A partir da década de 1960, com a demonstração de que a nitrofurazona (1) na dose diária de $100 \mathrm{mg} \mathrm{kg}^{-1} \mathrm{em}$ esquema terapêutico de prolongada duração (50 dias em média) curava mais de $95 \%$ dos camundongos cronicamente infectados, teve início uma nova era na terapêutica da doença de Chagas. ${ }^{22}$ Dez indivíduos com casos agudos da doença foram tratados com 1 apresentando bons resultados, contudo, metade voltou a manifestar a presença do parasita circulante detectado por técnicas xenodiagnóstico. ${ }^{22}$

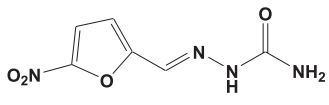

1

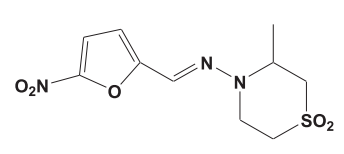

3

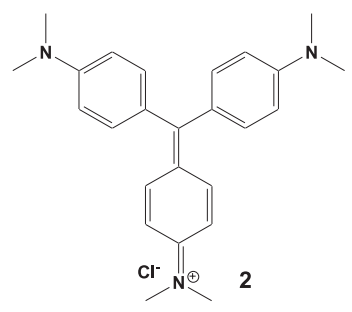

4

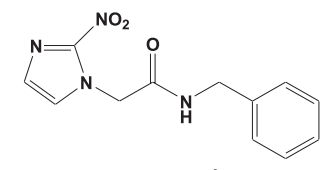

Figura 1. Estruturas químicas da nitrofurazona (1), violeta de genciana (2), nifurtimox (3) e benzonidazol (4)

Por volta do início da década de 1970, dois compostos surgiram apresentando novas perspectivas para o tratamento da doença de Chagas, tanto pela eficácia na fase aguda quanto pela tolerância. Estes são o nifurtimox (Lampit ${ }^{\circledR}$, da Bayer), 3-metil-4-(5'nitrofurfurilidenoamino)tetra-hidro-4H-1,4-tiazina-1,1-dióxido (3) (Figura 1); e o benzonidazol (Rochagan ${ }^{\circledR}$, da Roche), N-benzyl-2nitroimidazol acetamida (4) (Figura 1). ${ }^{20} \mathrm{~A}$ ação destes fármacos é afetada diretamente por algumas condições, como a duração do tratamento, a idade e a distribuição geográfica dos pacientes, entre outros. Os resultados mais promissores foram observados na fase aguda da doença com o uso de 3 na dose de $8-10 \mathrm{mg} \mathrm{kg}^{-1}(\approx 35 \mu \mathrm{mol}$ $\left.\mathrm{kg}^{-1}\right)$ e de 4 na dose de 5-7,5 $\mathrm{mg} \mathrm{kg}^{-1}\left(\approx 30 \mu \mathrm{mol} \mathrm{kg} \mathrm{kg}^{-1}\right)$, durante um período de 60 a 90 dias. ${ }^{23-25}$ Por outro lado, em pacientes adultos na fase crônica da infecção, os melhores resultados foram obtidos no Cone Sul da América do Sul (região sul do Brasil, Argentina e Chile) devido provavelmente ao tipo de cepa de $T$. cruzi predominante nesta região. ${ }^{23-26}$ Os fármacos 3 e 4 apresentaram entre 50 e $70 \%$ de cura na fase aguda, em contraste com valores percentuais inferiores a 20 na fase crônica da doença. ${ }^{23}$

Evidências indicam que o nifurtimox (3) e benzonidazol (4) atuam através da formação de radicais livres e/ou metabólitos eletrofílicos (Figura 2). O grupo nitro $\left(\mathrm{NO}_{2}\right.$ ) presente nestas moléculas é reduzido ao grupo amino $\left(\mathrm{NH}_{2}\right)$ pela ação de enzimas do tipo nitroredutases, que atuam especificamente em sistemas moleculares do tipo $\mathrm{R}-\mathrm{NO}_{2}$. Este processo, iniciado pela reação catalisada pela NADPH citocromo P450 redutase (EC 1.6.2.4), leva à formação de um intermediário nitro radicalar $\left(\mathrm{R}-\mathrm{NO}_{2}{ }^{-}\right)$com subsequente formação de hidroxilamina (R-NHOH) ${ }^{27}$ No caso de $\mathbf{3}$, o radical reduz o oxigênio molecular $\left(\mathrm{O}_{2}\right)$ formando o íon superóxido $\left(\mathrm{O}_{2}{ }^{-}\right)$ e regenerando o grupo $\mathrm{NO}_{2}$ num processo conhecido como ciclo redox (redox ciclyng). ${ }^{27} \mathrm{O}$ íon superóxido formado é captado pela enzima superóxido dismutase (EC 1.15.1.1) gerando peróxido de hidrogênio $\left(\mathrm{H}_{2} \mathrm{O}_{2}\right)$ que, através da reação de Haber-Weiss na presença de íons $\mathrm{Fe}^{\text {III }}$, forma o radical hidroxila $\left({ }^{\bullet} \mathrm{OH}\right) .{ }^{28,29} \mathrm{~A}$ esta espécie tem sido atribuído o efeito tripanocida por mecanismos complexos que envolvem ligação a lipídeos, proteínas e ao DNA do T. cruzi. ${ }^{27}$ Por outro lado, o fármaco 4 não atua através do ciclo redox e não depende diretamente de espécies reativas de oxigênio (ROS - reactive oxigen species). ${ }^{27} \mathrm{O}$ radical nitro formado em 4 estaria envolvido com seu efeito tripanocida através da formação de ligações covalentes com macromoléculas do T. cruzi (e.g., DNA e citocromo P450). ${ }^{28}$ É descrito ainda que 4 aumenta a fagocitose e lisa o T. cruzi através de um mecanismo dependente de interferongama (IFN- $\gamma$ - interferon-gamma), ${ }^{29} \mathrm{e}$ inibe o crescimento do $T$. cruzi através da enzima NADH-fumarato redutase (EC 1.3.1.6). ${ }^{30}$ 


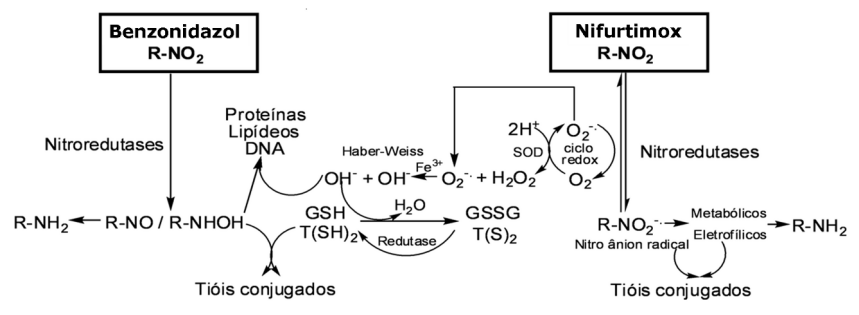

Figura 2. Mecanismo de ação proposto dos fármacos nifurtimox (3) e benzonidazol (4)

Os metabólitos (eletrofílicos) formados através do mecanismo de ação de 3 e 4 podem atuar também em outros sistemas, especialmente do hospedeiro (humano), devido a sua alta reatividade. Esta baixa especificidade de ação em vias bioquímicas definidas do parasita contribui para os efeitos citotóxicos observados no tratamento dos pacientes. Os efeitos mais comuns para o composto 3 são perda de peso, sonolência, além de algumas manifestações digestivas, tais como náuseas, vômitos e cólicas intestinais. ${ }^{31}$ Já para o fármaco 4, os efeitos colaterais mais frequentes podem ser agrupados de três formas: (i) manifestações de hipersensibilidade, como dermatite com erupção cutânea (usualmente entre o $7^{\circ}$ e $10^{\circ}$ dia de tratamento), edema periorbital ou generalizado, febre, linfadenopatia, dores musculares e articulares; (ii) depressão da medula óssea, incluindo neutropenia, agranulocitose e púrpura trombocitopêmica; e (iii) polineuropatia periférica, representada por parestesias e polineurite. ${ }^{31}$

\section{ESTADO DA ARTE E PERSPECTIVAS NO DESENVOLVIMENTO DE NOVOS FÁRMACOS}

O processo de descoberta e desenvolvimento de novos fármacos engloba várias estratégias e uma combinação de métodos tradicionais e modernos, de natureza intrinsecamente multi- e interdisciplinar, integrando especialidades como a química, biologia, medicina, farmácia, bioquímica, farmacologia, bioinformática, entre outras. A ação dos fármacos pressupõe a interação de uma molécula pequena (ligante) com uma macromolécula (receptor biológico), tipicamente uma proteína de alguma via bioquímica associada a uma condição de doença ou disfunção em humanos. ${ }^{32-34}$ Por muitas décadas, a descoberta de substâncias bioativas se baseou em química e biologia básica e em uma abordagem "tentativa e erro" guiada por modelos experimentais em culturas de células (in vitro) ou em animais (in vivo). A evolução desse processo deu origem à era do planejamento de fármacos, que teve como elemento fundamental a mudança de paradigma caracterizada pelo entendimento de que os sistemas químicos tinham papel determinante na modulação de sistemas biológicos. ${ }^{33-35}$

As doenças endêmicas parasitárias representam um grave problema médico, social e humano e sua prevenção, controle e tratamento representam um grande desafio mundial. Por outro lado, do ponto de vista científico, as oportunidades de estudos na área de planejamento de fármacos são promissoras, especialmente nas últimas décadas com os avanços da biologia molecular e estrutural, bem como da química medicinal e computacional, da síntese orgânica planejada e dos ensaios biológicos em larga escala. As doenças parasitárias recebem grande atenção no Programa Especial para Pesquisa e Treinamento em Doenças Tropicais (TDR - Special Programme for Research \& Training in Tropical Diseases) da OMS. ${ }^{32}$ Para as doenças infectoparasitárias consideradas prioritárias neste programa, como a malária, doença de Chagas, esquistossomose, tripanossomíase africana e as leishmanioses, não existem vacinas disponíveis e os fármacos permanecem o centro do controle destas doenças. Contudo, o repertório de fármacos disponíveis é limitado e inadequado, e o quadro é bastante agravado pela emergência de cepas de parasitas resistentes. Novos fármacos são necessários imediatamente e continuarão a ser no futuro, uma vez que os parasitas acabam desenvolvendo, através de mecanismos diversos, resistência aos quimioterápicos mais frequentemente usados. ${ }^{32-37}$

O aumento considerável nos investimentos requeridos no desenvolvimento de novos fármacos, aliado à perspectiva de retornos financeiros insuficientes, tem como resultado a quase inexistência de recursos em P\&D na área de doenças parasitárias por parte das principais companhias farmacêuticas e biotecnológicas do mundo. Neste panorama atual, a doença de Chagas pode ser considerada extremamente negligenciada, o que ilustra uma realidade preocupante face às necessidades das populações mais pobres e vulneráveis do planeta. ${ }^{2,3,32}$ A produção de medicamentos também segue uma tendência de mercado, já que os maiores produtores são a América do Norte (50\%), Europa (24\%) e Japão (13\%). A América Latina é responsável por apenas $5 \%$ dos medicamentos produzidos no mundo, sendo que outras regiões mais pobres do planeta apresentam números insignificantes ou participação nula. ${ }^{3,33}$

As pesquisas por novos fármacos para o tratamento da doença de Chagas têm evoluído sensivelmente nas últimas décadas, com destaque para o sequenciamento dos genomas do T. cruzi, T. brucei e Leishmania. ${ }^{34-36}$ que permitiu a identificação de vários genes, muitos deles existentes apenas no parasita e não no homem. Além disso, várias moléculas pequenas vêm sendo exploradas em programas de química medicinal com a aplicação de métodos de planejamento de fármacos baseados na estrutura do receptor (SBDD - structure-based drug design) e na estrutura do ligante (LBDD - ligand-based drug design). As inovações científicas e tecnológicas têm contribuído fortemente no direcionamento do processo moderno de P\&D na área de doenças negligenciadas. No tópico a seguir dar-se-á ênfase à doença de Chagas, explorando as bases moleculares para a identificação e seleção de proteínas alvo e a descoberta e otimização de moléculas bioativas candidatas a fármacos.

\section{Aspectos biológicos e químicos: alvos macro- e micromoleculares}

Além dos avanços significativos obtidos nos aspectos biológicos, genéticos e evolucionários do parasita, o sequenciamento do genoma do T. cruzi também contribui com a identificação de diversos alvos biológicos promissores, sendo a maior parte de enzimas. ${ }^{34-37} \mathrm{Na}$ Tabela 1 são apresentados alguns dos alvos macromoleculares mais explorados e suas respectivas funções biológicas. Na sequência serão explorados alguns destes alvos, bem como a sua implicação no processo de desenvolvimento de novos fármacos através de modulação seletiva por moléculas pequenas. ${ }^{35}$

\section{Proteases}

São enzimas que quebram ligações peptídicas entre aminoácidos de proteínas e peptídeos. Estima-se que sem a participação catalítica destas enzimas, a hidrólise de um único peptídeo poderia levar centenas ou milhares de anos, sendo que a reação ocorre em uma escala de milissegundos na presença da protease apropriada ${ }^{38}$ Em protozoários como o T. cruzi, as proteases possuem múltiplas funções que envolvem desde a invasão celular até o escape do parasita do sistema imune do hospedeiro..$^{34,37,38}$ Considerando-se o papel essencial dessa classe de enzimas no ciclo de vida do T. cruzi, algumas proteases têm sido selecionadas como alvos para o desenvolvimento de novos agentes antichagásicos. Cisteíno proteases, serino proteases, metaloproteínas e treonino proteases (Tabela 1) são exemplos de proteases amplamente estudadas. ${ }^{34,37}$ Dentre estas, a cruzaína (EC 3.4.22), também chamada cruzipaína ou GP57/51 (Figura 3), que constitui a mais abundante 
Tabela 1. Rotas metabólicas e alvos macromoleculares para o desenvolvimento de novos fármacos para o tratamento da doença de Chagas

\begin{tabular}{lc}
\hline $\begin{array}{l}\text { Alvo, via ou classe metabólica } \\
\text { (função) }\end{array}$ & $\begin{array}{c}\text { Enzima, organela } \\
\text { ou rota metabólica }\end{array}$ \\
\hline Proteases & Cisteíno proteases \\
(Múltiplas funções que envolvem & Serino proteases \\
desde invasão celular a escape \\
do parasita do sistema imune) & Metaloproteínas \\
& Treonino proteases \\
\hline Biossíntese de esteróis & Esterol 14-demetilase \\
(Essencial para a composição estrutural & Lanoesterol sintase \\
de membranas, mitocôndria e plasma) & Esqualeno epoxidase \\
& Esqualeno sintase \\
& 3-Hidroxi-3-metilglutaril coenzima \\
& A redutase \\
Via glicolítica & Farnesilpirofosfato sintase \\
(Produção de energia) & Farnesiltransferase \\
\hline Biossíntese de lipídeos & Gliceraldeído-3-fosfato desidroge- \\
(Essencial em diversos & nase \\
constituintes celulares) & Hexoquinase \\
\hline Metabolismo dependente & Fosfofrutoquinase \\
de grupos tióis & Alquil-lisofosfolipídeos \\
(Mecanismo de defesa & Glicosfingolipídeos \\
contra estresse oxidativo) & Tripanotiona redutase \\
\hline
\end{tabular}

Metabolismo de pentose fosfato

(Mecanismo de defesa

6-Fosfogluconato desidrogenase

contra estresse oxidativo)

\begin{tabular}{|c|c|}
\hline $\begin{array}{l}\text { Super família de proteínas quinases } \\
\text { (Produção de energia) }\end{array}$ & $\begin{array}{c}\text { Arginina quinase } \\
\text { Fosfatidilinositol-3 quinase }\end{array}$ \\
\hline $\begin{array}{l}\text { Transporte e metabolismo de poliaminas } \\
\text { (Defesa contra estresse oxidativo) }\end{array}$ & $\begin{array}{c}\text { Arginina descarboxilase } \\
\text { Glutationil espermidina sintetase }\end{array}$ \\
\hline $\begin{array}{l}\text { Síntese de nucleotídeos } \\
\text { (Precursores da síntese } \\
\text { de materiais genéticos) }\end{array}$ & $\begin{array}{l}\text { Purina fosforibosil transferases } \\
\text { Di-hidrofolato redutase } \\
\text { Pteridina redutase } \\
\text { Di-hidro-orotato desidrogenase }\end{array}$ \\
\hline $\begin{array}{l}\text { Organelas celulares } \\
\text { (Funções diversas) }\end{array}$ & $\begin{array}{l}\text { Núcleo e cinetoplasto } \\
\text { Mecanismo de transporte de } \mathrm{Na}^{+} / \\
\mathrm{H}^{+} \\
\text {Componentes da membrana e } \\
\text { osmorregulação } \\
\text { Glicossomo e síntese de vitamina }\end{array}$ \\
\hline
\end{tabular}

Transferência de ácido siálico

(Transferência do ácido a partir de

glicoconjugados do hospedeiro e

Trans-sialidase

incorporação em moléculas de mucina

ligadas à membrana parasitária)

\begin{tabular}{ll}
\hline DNA topoisomerases & DNA topoisomerase I \\
(Replicação do DNA do T. cruzi) & DNA topoisomerase II \\
\hline
\end{tabular}

proteína da família das cisteíno proteases do T. cruzi, tem sido muito explorada levando à descoberta de vários inibidores potentes e seletivos. Das patentes depositadas através da Organização Mundial da Propriedade Intelectual (WIPO - World Intellectual Property Organization) sobre moduladores de rotas metabólicas do T. cruzi, os inibidores de cruzaína merecem especial destaque. As principais classes de inibidores desta enzima incluem (Figura 3): (i) derivados peptídicos (5 e 6); ${ }^{34}$ (ii) derivados não-peptídicos (triazóis 7, pirimidinas 8, tiossemicarbazonas 9 e chalconas 10); ${ }^{34-40}$ (iii) complexos de rênio e ouro (oxorênios 11 e ciclometalados de ouro 12); ${ }^{41}$ e (iv) doadores de óxido nítrico (nitrosotióis 13 e nitrosilo complexos de ferro e rutênio 14). ${ }^{42,43}$ Os derivados peptídicos constituem a classe mais importante de inibidores da cruzaína, especialmente o dipeptidil vinil sulfônico $N$-metil-Pip-F-hF-VS $\phi$ (5) ${ }^{39}$ Este inibidor, além de alta seletividade, também exibiu potente atividade in vitro e in vivo, inclusive em modelos imunossuprimidos de infecção experimental aguda de doença de Chagas.

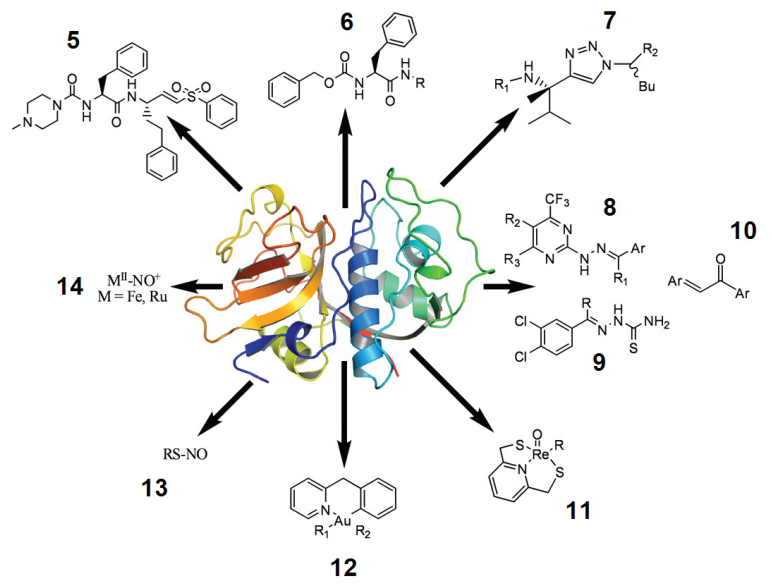

Figura 3. Estrutura cristalográfica da cruzaína de T. cruzi (PDB ID 1ME4). Inibidores da enzima alvo de diferentes classes químicas (5-14)

A diversidade química dos inibidores da Figura 3 representa o espaço químico biológico que pode ser explorado, valorizando o papel dos produtos naturais e da síntese orgânica como fontes valiosas de moléculas privilegiadas capazes de interagir com sistemas biológicos complexos.

\section{Biossíntese de esteróis}

Os esteróis são componentes essenciais às membranas das células e podem ser produzidos por animais e plantas. Além disso, são precursores da biossíntese de diversos hormônios e da vitamina D. No caso dos organismos unicelulares, os esteróis são essenciais ao crescimento celular. O principal esterol para o crescimento do T. cruzi é o ergosterol, o que torna, portanto, a via de biossíntese desse lipídeo um alvo atrativo para o desenvolvimento de fárma$\cos .{ }^{34} \mathrm{~A}$ importância dessa via bioquímica pode ser melhor avaliada considerando-se que depois dos fármacos 3 e 4 (Figura 1), os inibidores da biossíntese de esteróis são os únicos que alcançaram triagens clínicas avançadas como candidatos a fármacos anti- $T$. cruzi. Atualmente, as enzimas mais bem estudadas desta cascata metabólica são a esterol 14-demetilase (EC 1.14.13.70), lanoesterol sintase (EC 5.4.99.7), esqualeno epoxidase (EC 1.14.99.7), esqualeno sintase (EC 2.5.1.21), $\Delta$-24(25) esterol metiltransferase (EC 2.1.1.43), farnesilpirofosfato sintase (EC 2.5.1.10) e a farnesiltransferase (EC 2.5.1.58) (Tabela 1). Dentre os inibidores mais representativos da síntese de ergosterol têm-se os derivados azólicos inibidores da esterol 14-demetilase, cetoconazol (15), fluconazol (16) e itraconazol (17), além do inibidor da farnesiltransferase, tipifarnib (18) (Figura 4).

O potencial da classe de derivados azólicos pode ser observado no caso dos inibidores 17 e 18, que além de exibirem alta seletividade enzimática, induziram cura parasitológica em modelos animais de infecção aguda e crônica. ${ }^{45,46}$ É interessante observar que os compostos da Figura 4 apresentam propriedades antifúngicas conhecidas e foram 
incluídos em processos de triagens antiparasitária, como estratégia útil para a identificação de candidatos a novos fármacos com menor tempo e custo. ${ }^{32,34}$ Contudo, o uso destes compostos é limitado pela baixa absorção e resistência. ${ }^{34}$ Novas gerações de compostos desta classe deverão incorporar melhores características físico-químicas com o objetivo de otimizar propriedades farmacocinéticas, como absorção e biodisponibilidade. ${ }^{47}$

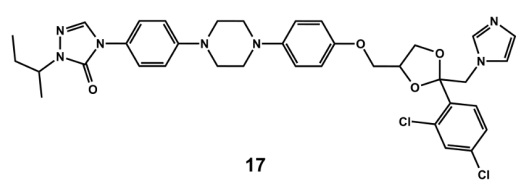

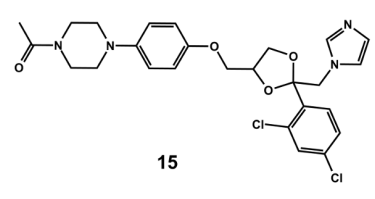
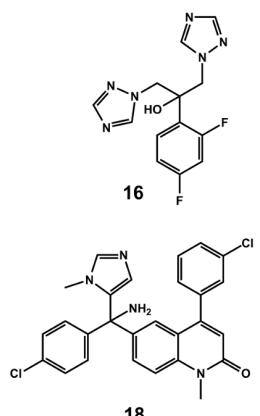

Figura 4. Inibidores azólicos cetoconazol (15), fluconazol (16), itraconazol (17) e tipifarnib (18)

\section{Via glicolítica}

Formas tripomastigotas do T. cruzi são desprovidas do ciclo do ácido tricarboxílico. ${ }^{48}$ Levando-se em consideração que estas formas infectivas são altamente dependentes da via glicolítica como fonte de energia através da produção de ATP, esta se torna, portanto, um alvo atrativo para o desenvolvimento de novos agentes quimioterápicos para a doença de Chagas. ${ }^{48,49}$ Podem-se destacar ao menos três enzimas que têm sido bastante exploradas como alvos biológicos: a gliceraldeído-3-fosfato desidrogenase (GAPDH, EC 1.2.1.12) (Figura 5), a hexoquinase (EC 2.7.1.1), e a fosfofrutoquinase (EC 2.7.1.11) ${ }^{49,50}$ A GAPDH é uma enzima tetramérica que catalisa a conversão do substrato gliceraldeído-3-fosfato em 1,3-bisfosfoglicerato, na presença do cofator $\mathrm{NAD}^{+} \mathrm{e}$ fosfato inorgânico. A hexoquinase cliva adenosina trifosfato (ATP) em adenosina difosfato (ADP), enquanto que a fosfofrutoquinase catalisa a transferência irreversível de um fosfato de ATP a frutose-6-fosfato. ${ }^{50}$

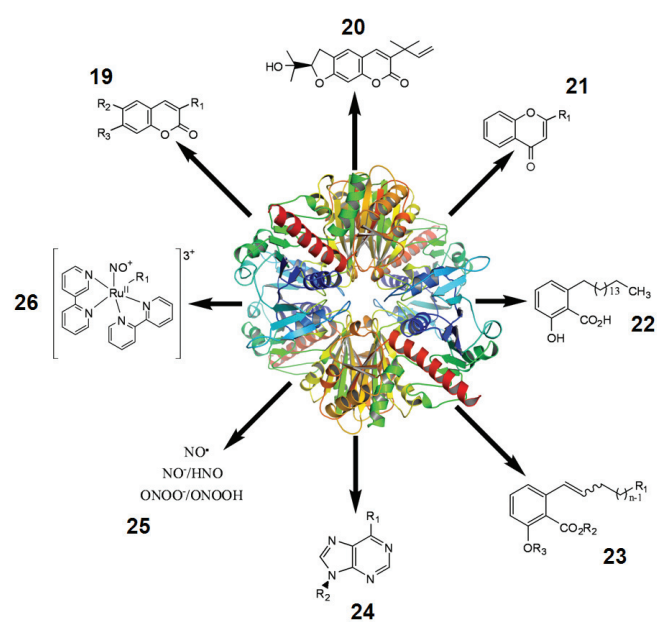

Figura 5. Estrutura cristalográfica da enzima GAPDH de T. cruzi (PDB ID 3DMT). Inibidores de origem natural e sintética da enzima alvo (19-26)

Dentre as enzimas da via glicolítica, a GAPDH tem sido alvo de muitos estudos em química medicinal e como resultado vários inibidores de origem natural e sintética, com boa diversidade química, têm sido descobertos. Dentre estes, destacam-se as cumarinas (19, 20), flavonoides (21) e ácidos anacárdicos (22) de origem natural; os derivados de produtos naturais como os análogos sintéticos do ácido anacardíaco (23); os compostos sintéticos derivados de planejamento racional como os nucleosídeos (24); os reativos intermediários de nitrogênio (óxido nítrico, nitroxil e peroxinirito) (25); e mais recentemente alguns complexos doadores de NO (26)..$^{51-56}$

\section{Metabolismo dependente de grupos tióis}

O principal mecanismo de defesa do T. cruzi contra o estresse oxidativo envolve os tióis tripanotiona (27), homotripanotiona (28), glutationa (29) e ovotiol (30) (Figura 6). ${ }^{57}$ Tal hipótese é suportada pelo fato de que nenhuma catalase ou glutationa peroxidase é encontrada no parasita e a atividade da superóxido dismutase é muito reduzida. ${ }^{58}$ Além disso, não há evidências da existência de $\alpha$-tocoferol ou $\beta$-caroteno no T. cruzi, ao contrário do que ocorre em células mamíferas, que se protegem eficazmente dos radicais livres através de mecanismos enzimáticos e não enzimáticos. ${ }^{59}$ Seria possível depreciar cerca de $90 \%$ da síntese de glutationa em células mamíferas sem causar efeitos deletérios sobre estas células, o que não ocorreria no caso do T. cruzi, que é deficiente de mecanismos de defesa contra radicais livres. ${ }^{27}$ Desta forma, uma redução nos níveis dos tióis antioxidantes do T. cruzi tornaria o parasita altamente susceptível aos efeitos de radicais livres (e.g., $\mathrm{NO}^{\bullet}, \mathrm{O}_{2}^{\bullet}$ ou $\mathrm{ONOO}^{-}$). Merecem destaque especial na via de biossíntese de tióis as enzimas tripanotiona redutase (EC 1.8.1.12) e tripanotiona sintetase (EC 3.6.1.9), que têm sido bastante exploradas como alvos para o desenvolvimento de fármacos. A primeira é responsável pela manutenção dos níveis de tripanotiona reduzida e a segunda pela adição do composto 29 ao substrato glutationil espermidina, formando tripanotiona (27). ${ }^{27,34-36}$ A enzima triparedoxina peroxidase também apresenta importância considerável na exposição do T. cruzi as ROS. ${ }^{60}$

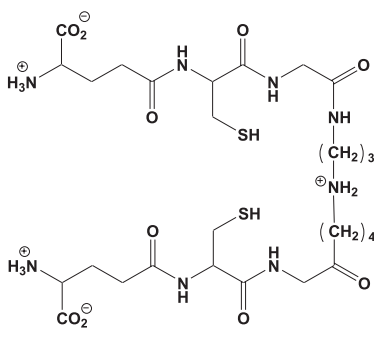

27<smiles>NC(CCC(=O)NC(CS)C(=O)NCC(=O)O)C(=O)O</smiles>

29<smiles>CCCCCCCNC(=O)CNC(=O)C(CS)NC(=O)CCC(N)C(=O)[O-]</smiles><smiles>NCCCCCCC(=O)CNC(=O)C(CS)NC(=O)CCC(N)C(=O)O</smiles>

28

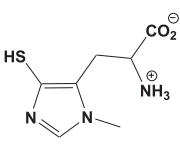

30
Figura 6. Principais tióis de tripanosomatídeos: tripanotiona (27), homotripanotiona (28), glutationa (29) e ovotiol (30)

\section{Transferência de ácido siálico}

A trans-sialidase pertence à família de glicoproteínas de superfície do T. cruzi e constitui um dos poucos exemplos de glicosiltransferases superficiais encontradas em eucariontes. ${ }^{61}$ Essa enzima tem duas atividades, uma hidrolase e outra transferase, e catalisa preferencialmente a transferência de ácido siálico para moléculas de mucina, originando ligações $\alpha$-2,3 com moléculas de $\beta$-galactose aceptoras na superfície do parasita. Apesar de ser classificada principalmente como transferase, promovendo reações reversíveis, a trans-sialidase possui também ação residual hidrolítica (Figura 7). Como o T. cruzi 
é incapaz de sintetizar ácido siálico e o único mecanismo de transferência deste ácido é através da trans-sialidase, esta enzima tem se tornado um alvo macromolecular promissor. ${ }^{34}$

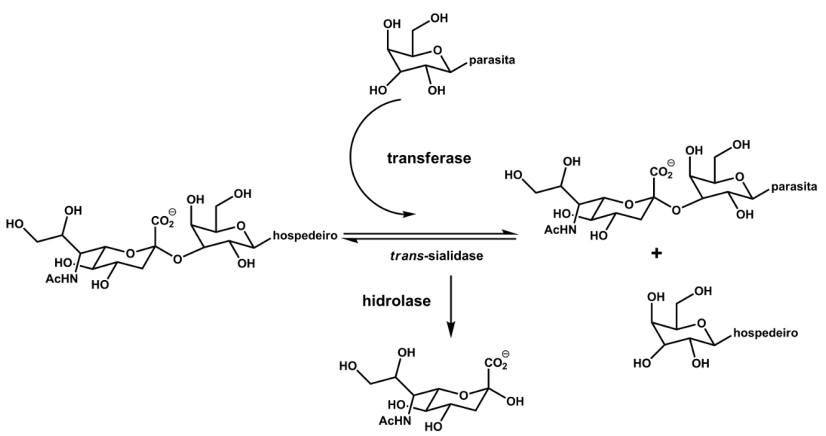

Figura 7. Reação de transferência de ácido siálico mediada pela trans-sialidase

\section{DNA topoisomerases}

As enzimas DNA topoisomerases I (EC 5.99.1.2) e II (EC 5.99.1.3) têm atraído grande atenção da comunidade científica, pois desempenham papel essencial na replicação do DNA do T. cruzi e, em particular, no processo de replicação da cadeia de minicírculos e maxicírculos do DNA do kinetoplasto (kDNA). O planejamento de inibidores destas isomerases representou grande sucesso no desenvolvimento de novos agentes quimioterápicos citotóxicos. ${ }^{62}$ Existem alguns fármacos antioneoplásicos disponíveis comercialmente que atuam nesses alvos (Figura 8), tais como os inibidores da topoisomerase I, irinotecano (Camptosar ${ }^{\circledR}$, da Pfizer) (31) e topotecana (Hycamtin ${ }^{\circledR}$, da GlaxoSmithKline) (32); e os inibidores da topoisomerase II, etoposida (33) e teniposida (34) (Vepesid $^{\circledR}$ e Vumon ${ }^{\circledR}$, respectivamente, da Bristol-Myers Squibb). As antraciclinas, camptotecinas, acridinas e fluoroquinolonas formam classes de inibidores bem conhecidas, as quais apresentaram bons resultados contra formas tripomastigotas sanguíneas do T. cruzi.
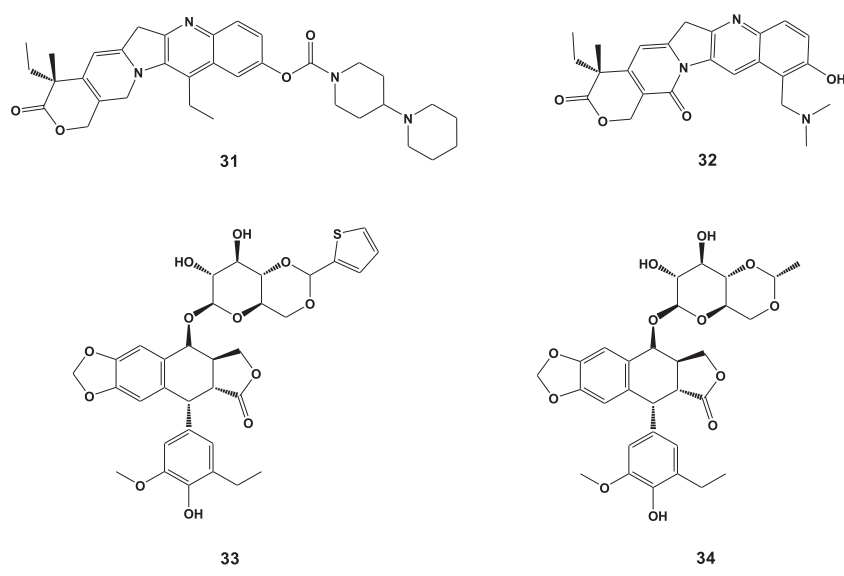

Figura 8. Antineoplásicos inibidores das topoisomerases I e II

\section{PLANEJAMENTO DE MOLÉCULAS BIOATIVAS: INTEGRAÇÃO ENTRE QUÍMICA MEDICINAL E QUÍMICA ORGÂNICA SINTÉTICA}

Entre as estratégias mais utilizadas no planejamento de agentes antiparasitários está a investigação de vias bioquímicas e a seleção de proteínas alvo dos patógenos, que possam, por sua vez, ser moduladas especifica ou seletivamente por pequenas moléculas, considerandose a presença ou ausência do alvo no hospedeiro. Neste contexto, as várias enzimas que vêm sendo estudadas para o desenvolvimento de novos fármacos fornecem exemplos muito interessantes de estratégias multidisciplinares, com diversos níveis de complexidade e de incorporação de métodos e tecnologias de planejamento. ${ }^{63,64}$ Os avanços significativos da biologia molecular e estrutural têm possibilitando a seleção e validação de vários alvos biológicos importantes, especialmente na era pós-genômica. $\mathrm{O}$ aprimoramento das técnicas de determinação estrutural de macromoléculas, como a cristalografia de raios $\mathrm{X}$ e a ressonância magnética nuclear (RMN), tem contribuído fundamentalmente na compreensão das interações intermoleculares predominantes entre moléculas bioativas e seus receptores biológicos, bem como nos estudos de caracterização de mecanismos de ação. Vale salientar que há vários outros casos de moléculas que possuem interessante atividade anti-T. cruzi in vitro, contudo, a via bioquímica e o alvo molecular não são conhecidos. ${ }^{65}$

A rápida identificação de moléculas bioativas e a otimização de compostos líderes têm se tornado questões prioritárias na área de doenças negligenciadas. Os pró-fármacos também merecem destaque especial, pois a biotransformação da forma inativa do fármaco, liberando a porção ativa no local de ação ou próximo a este, é uma estratégia muito útil no planejamento de quimioterápicos com alta especificidade de ação. ${ }^{66}$ A grande disponibilidade de compostos sintéticos e de ensaios biológicos em média e larga escala tem contribuído para a seleção de várias moléculas com diferentes tipos de atividades biológicas e farmacológicas. Uma questão fundamental que se coloca à frente nesse processo é a otimização de moléculas promissoras em relação a propriedades como potência e afinidade. A execução dessa tarefa desafiadora requer a integração entre as estratégias de química medicinal moderna e o planejamento em química orgânica sintética, para que novas moléculas, capazes de representar novas entidades químicas (NCEs - new chemical entities) possam ser geradas..$^{53,63}$

Diversas estratégias de otimização de compostos com atividade anti-T. cruzi são descritas na literatura, variando desde os modelos tradicionais baseados na abordagem "tentativa e erro", até os métodos mais modernos de SBDD e LBDD, guiados pelo uso racional de inovações científicas e tecnológicas. Neste tópico são apresentados dois exemplos do emprego da síntese orgânica na geração de moléculas promissoras para a terapia da doença de Chagas, abordando alguns aspectos sensíveis do planejamento, com ênfase nas etapas de síntese dos compostos e otimização de propriedades. O entendimento desses processos é de fundamental importância nos estudos das relações entre a estrutura e atividade (SAR - structure-activity relationships) e no planejamento de novas moléculas bioativas. No primeiro exemplo, o grupo $N$-óxido foi explorado para o desenvolvimento de vários derivados benzofuroxanos (benzo[1,2-c]1,2,5-oxadiazol $N$-óxido) para avaliação biológica (Figura 9). O processo de planejamento tinha como objetivo a geração de compostos mais seletivos frente ao parasita, explorando as qualidades biorredutíveis superiores do grupo $N$-óxido em relação àquelas dos fármacos 3 e 4 (Figura 1) ${ }^{67}$ É interessante observar que alguns derivados heterocíclicos $N$-óxidos, isômeros tautoméricos de $N$-hidroxi-benzimidazóis, apresentaram modesta atividade in vitro, resultado que foi atribuído ao fato destes derivados não serem $\mathrm{N}$-óxidos verdadeiros (Figura 9). ${ }^{68,69}$
A<smiles>[O-][n+]1onc2ccc[R]c21</smiles>

benzofuroxano
B

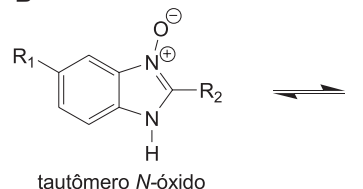

tautômero $N$-hidróx

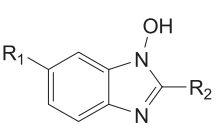

Figura 9. A. Estrutura geral dos derivados benzofuroxanos; B. formas tautoméricas $N$-óxido e $N$-hidróxi de derivados heterocíclicos de benzimidazóis 
Com base nisso foi planejada uma nova série de derivados $N$-óxido-benzimidazóis não tautomerizáveis e a atividade in vitro foi determinada contra a forma epimastigota de $T$. cruzi. ${ }^{70}$ Com o intuito de aumentar a diversidade química e melhorar algumas propriedades físico-químicas desta classe de compostos, as estratégias de ciclização de $o$-nitro-anilinas e de reação de derivados de benzofuroxanos com 2-bromoacetato, iodeto de pentila e nitroalcanos foram empregadas com sucesso. ${ }^{71} \mathrm{Na}$ primeira estratégia, a ciclização térmica de $o$ nitro-anilinas catalisada por ácido conduziu a uma série de derivados $N$-óxido1H-benzimidazóis (35-39) contendo um substituinte no nitrogênio na posição 1, com rendimentos apenas moderados (Figura 10). ${ }^{70,71}$ Outras condições como a utilização de ácidos orgânicos e irradiação por micro-ondas foram testadas, mas não levaram a rendimentos superiores, devido provavelmente à baixa reatividade das nitro-anilinas usadas. Os derivados benzimidazóis $N$-óxidos verdadeiros (35-39) não inibiram in vitro o crescimento da forma epimastigota do T. cruzi na concentração de $25 \mu \mathrm{M}$, indicando que apenas o grupo $N$-óxido não era suficiente para conferir atividade biológica a esta série de compostos.
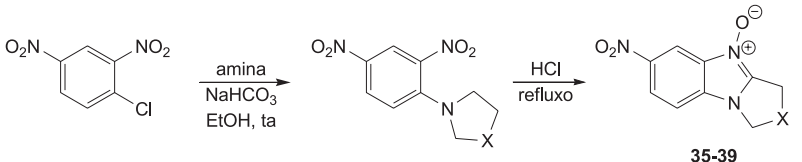

35-39

Figura 10. Esquema geral de síntese de $N$-óxidolH-benzimidazóis, sendo $X$ $=-\mathrm{CH}_{2}-(35),-\left(\mathrm{CH}_{2}\right)_{2}-(36),-\mathrm{CH}_{2} \mathrm{O}-(37),-\mathrm{CH}_{2} \mathrm{~S}-(38),-\mathrm{CH}_{2} \mathrm{~N}(\mathrm{Ph})-(39), \mathrm{com}$ rendimentos entre 19 e $46 \%$

Na segunda estratégia, os derivados benzimidazólicos 40-42 (Figura 11) foram obtidos pela reação dos benzofuroxanos correspondentes, selecionados a partir de uma coleção de compostos bioativos, com nitroetano em meio básico a temperatura ambiente. Os derivados benzofuroxanos substituídos na posição 5 do anel aromático (41 e 42) conduziram a misturas isoméricas (isômeros de posição 5 e 6) devido à presença do equilíbrio tautomérico mostrado na Figura 9. Estes derivados apresentaram baixa solubilidade em diferentes solventes orgânicos (metanol, acetona, DMSO) devido à alta polaridade conferida pelo grupo $N$-hidroxilamino livre do anel aromático. Diante disso, realizouse a reação de alquilação do grupo $\mathrm{OH}$ utilizando 2-bromo acetato de etila ou iodeto de $n$-pentila, conduzindo aos derivados 43-46 (isolados como misturas dos tautômeros). Em contraste com seus precursores, estes compostos apresentaram alta solubilidade em solventes orgânicos e modesta atividade inibitória (8-25\% de inibição). ${ }^{70}$

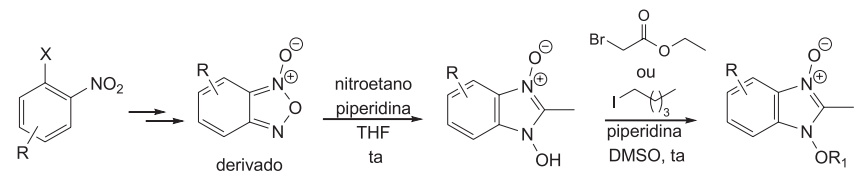

Figura 11. Reação de derivados benzofuroxanos com nitroalcanos, sendo $R=H(40) ; R=5(6)-\mathrm{CH}_{3}(\mathbf{4 1}) ; \mathrm{R}=5(6)-(\mathrm{E})-\mathrm{CH}=\mathrm{CHPh}(\mathbf{4 2}) ; \mathrm{R}=\mathrm{He} \mathrm{R}_{1}$ $=\mathrm{CH}_{2} \mathrm{CO}_{2} \mathrm{CH}_{2} \mathrm{CH}_{3}(43) ; \mathrm{R}=5(6)-\mathrm{CH}_{3}$ e $\mathrm{R}_{1}=\mathrm{CH}_{2} \mathrm{CO}_{2} \mathrm{CH}_{2} \mathrm{CH}_{3}(44) ; \mathrm{R}=$ 5(6)-(E)-CH=CHPh e $\mathrm{R}_{1}=\mathrm{CH}_{2} \mathrm{CO}_{2} \mathrm{CH}_{2} \mathrm{CH}_{3}(45) ; \mathrm{R}=\mathrm{H}$ e $\mathrm{R}_{1}=$ n-pentila (46). Rendimentos entre 34 e $61 \%$ para 40-42 e entre 34 e $52 \%$ para $43-46$

Com base na premissa da suposta atividade inibitória promissora dos derivados $N$-óxidos (verdadeiros), foram sintetizados novos benzofuroxanos com o emprego de 2-nitropropano e piperidina (Figura 12). Esta estratégia sintética impossibilitou a formação de isômeros funcionais dos derivados 1,3-dióxido de $2 H$-benzimidazóis (47-52). Os novos derivados foram obtidos em rendimentos acima de $60 \% \mathrm{e}$ apresentaram alta solubilidade em solventes orgânicos e água.

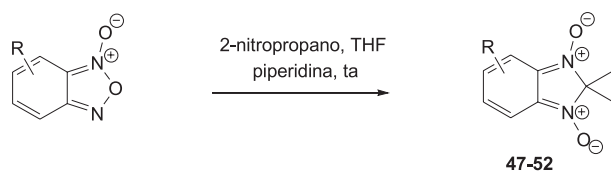

Figura 12. Reação de derivados benzofuroxanos com 2-nitropropano, sendo $R=$ $\mathrm{H}(47) ; 5-\mathrm{CH}_{3}(48), 5-\mathrm{OCH}_{3}(49) ; 5-\mathrm{Br}(50) ; 5-(\mathrm{E}) \mathrm{CH}=\mathrm{CHPh}(51) ; 5-\mathrm{CH}=\mathrm{NOH}$ (52); 5-CH=NNHCONH-n-hexil, com rendimentos entre 51 e $100 \%$

A avaliação biológica apresentou resultados interessantes para estes compostos (47-52), que na concentração de $25 \mu \mathrm{M}$ foram capazes de inibir entre 60 e $100 \%$ do crescimento das formas epimastigotas do T. cruzi in vitro (linhagem Tulahuen 2), confirmando as propriedades tripanocidas dos $N$-óxidos verdadeiros e o seu potencial para contínuo desenvolvimento. Diante disso, o parâmetro quantitativo de potência inibitória $\left(\mathrm{IC}_{50}\right.$, que se refere à concentração de composto necessária para inibir em $50 \%$ o crescimento do T. cruzi) foi determinado para os compostos 47-52 frente a diferentes linhagens do T. cruzi (Tulahuen 2 , CL Brener e Y). Os valores de $\mathrm{IC}_{50}$ obtidos foram muito promissores, com destaque para o composto $\mathbf{5 1}$ (mais potente da série) que apresentou $\mathrm{IC}_{50}$ de 3,6 e $5 \mu \mathrm{M}$ frente às cepas Tulahuen 2, CL Brener e Y, respectivamente. A toxicidade dos compostos 47-52 também foi investigada através de estudos de citotoxicidade inespecífica em macrófagos J774. Resultados interessantes foram obtidos para o composto 52, que não apresentou efeitos citotóxicos até uma concentração de $400 \mu \mathrm{M}$ (concentração 30 vezes maior que o valor de $\mathrm{IC}_{50}$ obtido frente às diferentes linhagens epimastigostas de T. cruzi). Em contraste, os derivados 47-51 apresentaram citotoxicidade moderada na faixa de 40 $\mu \mathrm{M}$. Além de ter a atividade in vitro e a toxicidade avaliadas em modelos apropriados, o desenvolvimento de moléculas bioativas candidatas a NCEs requer a avaliação da atividade tripanocida in vivo. Baseado nisso, o composto $\mathbf{5 2}$ foi avaliado in vivo usando um modelo animal (camundongos BALB/c infectados com a forma tripomastigota do $T$. cruzi). A taxa de sobrevida dos animais tratados com $\mathbf{5 2}$ foi de $100 \%$, ao passo que a do grupo controle (animais tratados com benzonidazol) variou entre 60 e $88 \% .{ }^{70}$ De modo geral, esses resultados ilustram como a síntese orgânica planejada auxilia no desenvolvimento e otimização de propriedades biológicas de novos compostos bioativos.

Como segundo exemplo tem-se o trabalho de planejamento, síntese e avaliação biológica (in vitro e in vivo) de uma série interessante de compostos heterocíclicos com promissora atividade contra tripanosomatídeos. ${ }^{72}$ Estes parasitas são auxotróficos por vários nutrientes, incluindo as purinas, as quais sequestram de seus hospedeiros a partir de transportadores especializados de nucleosídeos. Além da absorção das bases de purina como adenosina e adenina, um dos transportadores chamado de P2 (caracterizado em T. brucei) pode transportar derivados de melamina e benzamidina, que não são substratos para os correspondentes transportadores de mamíferos. ${ }^{73}$ A estratégia empregada neste trabalho envolveu o acoplamento do grupo melamina (fração de reconhecimento estrutural P2) a nitro-heterocíclicos, levando em consideração alguns requerimentos importantes para a absorção através do transportador P2, incluindo um grupo amidino, um anel aromático e um heteroátomo eletronegativo. Entre as características estruturais marcantes do composto líder da série $(\mathbf{5 3}),{ }^{74}$ pode-se destacar a presença de um grupo nitro, um fragmento triazina contendo o sistema amidínico, dois aneis aromáticos, heteroátomos e a presença da função hidrazona na fusão dos fragmentos de triazina e do anel contendo o grupo nitro, como pode ser observado na Figura 13.

Os estudos de SAR realizados levaram em consideração vários aspectos importantes na modificação molecular de $\mathbf{5 3}$ para a geração de novos compostos. ${ }^{72}$ As principais estratégias incluíram: (i) a introdução de grupos metila no fragmento triazina, com o objetivo de 
alterar as propriedades lipofílicas das moléculas; (ii) o emprego do bioisosterismo clássico como estratégia de modificação molecular, através da substituição do átomo de oxigênio por enxofre no anel heterocíclico contendo o grupo nitro; (iii) a variação de substituintes do anel de 5 membros com o propósito de avaliar os efeitos eletrônicos e as propriedades físico-químicas no sistema em estudo, bem como a própria importância da presença do grupo nitro.

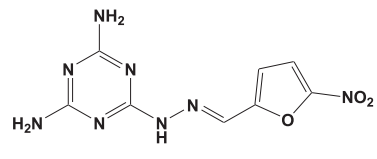

53

Figura 13. Estrutura química do composto líder da série (53)

Este é um exemplo bastante ilustrativo do papel chave da integração da química medicinal e da química orgânica sintética. Após o estabelecimento da estratégia de planejamento e das rotas sintéticas apropriadas, o trabalho de síntese iniciou com a reação da 2,4,6-tricloro-1,3,5-triazina (54) com amônia, metilamina e dimetilamina em acetona/ $\mathrm{H}_{2} \mathrm{O}$ como solvente, a temperatura ambiente, para fornecer os derivados 55-57, respectivamente, em bons rendimentos (Figura 14). Nas condições reacionais brandas que foram empregadas, apenas um dos átomos de cloro foi substituído, sendo possível introduzir primeiramente grupos amino derivados de aminas menos reativas. As cloro-triazinas (58-62) foram obtidas pela reação da amina correspondente com as 1,3,5-triazinas (55-57) na presença de base, em bons rendimentos. Tratamento de 58-62 com hidrazina em água, sob refluxo, forneceu as hidrazinas 63-67 em bons rendimentos (81-90\%). As hidrazonas 68-76 foram preparadas pelo tratamento das hidrazidas 63-67 com os aldeídos correspondentes, em rendimentos entre 13 e $80 \%$. Os derivados nitrados 77-79 (rendimentos de 17 a 77\%), preparados pelo tratamento de $\mathbf{6 3}$ com os correspondentes nitro-aldeídos, possuem um anel aromático monossubstituído (não-heterocíclico) em substituição ao anel heterocíclico de 5 membros (Figura 14).

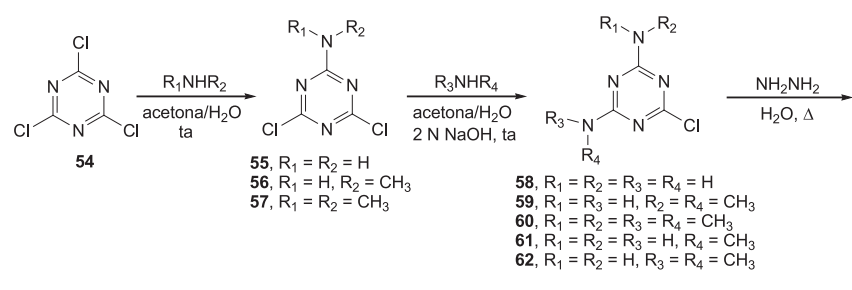

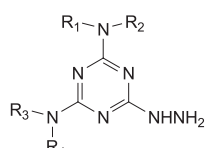

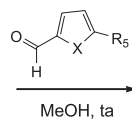

63, $R_{1}=R_{2}=R_{3}=R_{4}=H$ 64, $\mathrm{R}_{1}=\mathrm{R}_{3}=\mathrm{H}, \mathrm{R}_{2}=\mathrm{R}_{4}=\mathrm{CH}_{3}$ $65, \mathrm{R}_{1}=\mathrm{R}_{2}=\mathrm{R}_{3}=\mathrm{R}_{4}=\mathrm{CH}_{3}$ 66, $\mathrm{R}_{1}=\mathrm{R}_{2}=\mathrm{R}_{3}=\mathrm{H}, \mathrm{R}_{4}=\mathrm{CH}_{3}$ $67, R_{1}=R_{2}=H, R_{3}=R_{4}=C_{3}$
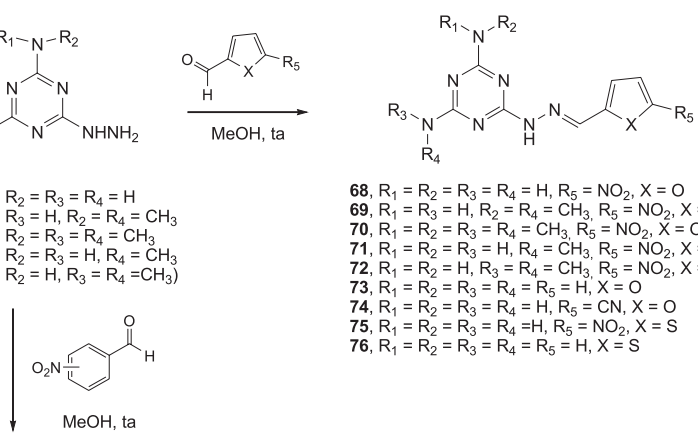

$68, R_{1}=R_{2}=R_{3}=R_{4}=H, R_{5}=N_{2}, X=O$ 69, $\mathrm{R}_{1}=\mathrm{R}_{3}=\mathrm{H}, \mathrm{R}_{2}=\mathrm{R}_{4}=\mathrm{CH}_{3}, \mathrm{R}_{5}=\mathrm{NO}_{2}, \mathrm{X}=\mathrm{O}$ , $\mathrm{R}_{1}=\mathrm{R}_{2}=\mathrm{R}_{3}=\mathrm{R}_{4}=\mathrm{CH}_{3}, \mathrm{R}_{5}=\mathrm{NO}_{2}, X=0$ 作, $73, R_{1}=R_{2}=R_{3}=R_{4}=R_{5}=H, X=O$ 74, $R_{1}=R_{2}=R_{3}=R_{4}=H, R_{5}=C N, X=0$ $75, R_{1}=R_{2}=R_{3}=R_{4}=H, R_{5}=N_{2}, X=$ $76, R_{1}=R_{2}=R_{3}=R_{4}=R_{5}=H, X=S$
,

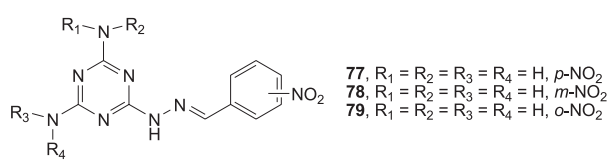

Figura 14. Síntese planejada e estudos de SAR
O acoplamento de derivados de poliaminas ao grupo melamina levou à obtenção de compostos com potente ação tripanocida e boa seletividade celular. ${ }^{75}$ Contudo, estes compostos demonstraram toxicidade elevada em modelos animais. Portanto, o composto líder $\mathbf{5 3}$ foi selecionado por apresentar uma fração estrutural alternativa com reconhecida atividade tripanocida, representada pelo grupo nitroaromático, para o acoplamento aos grupos melamina e benzamidina. Vale ressaltar que os fármacos $\mathbf{3}$ e $\mathbf{4}$ (Figura 1) empregados na terapia da doença de Chagas são nitro-heterocíclicos, que apresentam uma série de limitações. Sabe-se que um dos problemas com compostos nitroaromáticos é que alguns apresentam consideráveis efeitos mutagênicos, carcinogênicos e citotóxicos, contudo, isso não acontece em muitos casos e não pode ser tomado como regra geral, principalmente no caso de doenças em que não há alternativas terapêuticas disponíveis e novos fármacos são esperados com urgência. A alternativa de empregar o acoplamento de compostos nitro-aromáticos ao grupo melamina teve o objetivo de entregar de forma rápida e seletiva estes compostos aos parasitas, possibilitando doses reduzidas e efeitos colaterais reduzidos.

Os compostos preparados foram avaliados em relação à afinidade de interação pelo transportador P2. Compostos sem a presença do grupo melamina apresentaram baixa afinidade pelo transportador P2 (resultados não apresentados), como esperado. ${ }^{76} \mathrm{O}$ composto 70, que apresenta todos os átomos de nitrogênio do anel melamina metilados, também possui afinidade muito baixa $\left(\mathrm{IC}_{50}=129 \mu \mathrm{M}\right)$. Os demais compostos apresentaram valores de $\mathrm{IC}_{50}$ dentro de uma unidade logarítmica, em uma faixa de ordem similar à do derivado arsênico melarsoprol, que é um substrato do transportador P2, usado como medicamento no tratamento da tripanossomíase africana. Alterações no anel nitrofurano renderam apenas pequenas variações na afinidade aparente pelo transportador P2. A remoção do grupo nitro (comparação dos compostos nos pares 68/73 e 75/76) não levou a alterações significativas, ao passo que a presença de enxofre melhorou discretamente a afinidade. Esses estudos de SAR demonstraram que o fator principal para a afinidade do transportador P2 é a presença do anel melamina, enquanto que o nitro-heterocíclico tem efeito limitado.

Os compostos da série 77-79 foram também avaliados biologicamente contra o T. cruzi, já que apresentaram atividade in vitro contra T. brucei, independente da presença ou ausência do transportador P2, indicando que outras vias existem para estes compostos. Os compostos 68-72 e 74-79 apresentaram atividade tripanocida promissora (formas amastigotas), com valores de $\mathrm{IC}_{50}$ variando desde a faixa de melhor potência de 0,24 $0,39 \mu \mathrm{M}$, para os compostos $69\left(\mathrm{IC}_{50}=0,24 \mu \mathrm{M}\right), \mathbf{7 0}\left(\mathrm{IC}_{50}=0,38 \mu \mathrm{M}\right)$, $71\left(\mathrm{IC}_{50}=0,39 \mu \mathrm{M}\right)$ e $72\left(\mathrm{IC}_{50}=0,29 \mu \mathrm{M}\right)$, até a faixa de menor potência para os compostos 77-79 $\left(\mathrm{IC}_{50}=328 \mu \mathrm{M}\right) .^{72} \mathrm{~A}$ atividade dos melhores compostos foi investigada em modelo experimental de infecção com $T$. cruzi em camundongos. Os compostos 71 e 72 mostraram boa atividade in vivo, sendo que o composto $\mathbf{7 2}$ reduziu os níveis de parasitemia em $45 \%$ na dose de $50 \mathrm{mg} / \mathrm{kg}$. A estratégia empregada neste trabalho levou à geração de uma nova série de compostos com potente ação anti-T. cruzi, apresentando elevado potencial para o desenvolvimento de compostos líderes candidatos a novos fármacos antichagásicos.

\section{Contribuições da química inorgânica medicinal}

Além dos trabalhos tradicionais de planejamento, síntese orgânica e estudos de SAR discutidos nesse tópico, uma contribuição que merece especial destaque nas pesquisas de doenças negligenciadas é a da área de química inorgânica medicinal. Os primeiros relatos na literatura do uso de metais de transição na quimioterapia da doença de Chagas são referentes ao uso de sais de ouro, cobre e zinco durante os ensaios empíricos empregados no período correspondente à Fase II mencionada na parte de introdução desta revisão. ${ }^{22,23}$ A partir da década de 80 , muitos esforços foram direcionados na avaliação da ação anti-Trypanosoma 
de uma variedade de complexos com atividade antitumoral, devido principalmente às semelhanças bioquímicas em termos de metabolismo e recursos de sistemas de proteção entre os tripanosomatídeos e algumas células tumorais. ${ }^{55}$ Logo surgiram os primeiros trabalhos mostrando uma boa correlação entre as propriedades antitumorais e tripanostáticas de compostos de platina, como a cisplatina $(\mathbf{8 0})$ e carboplatina $(\mathbf{8 1})$ (Figura 15). ${ }^{56}$ Dentre os compostos de platina (II) mais promissores, podemos destacar os derivados terpiridínicos (2,2':6'2"'-terpiridina) e pentamidínicos, os quais foram eficazes in vitro contra as formas amastigotas e tripomastigotas do T. cruzi. A atividade tripanocida de uma série de complexos de amino ou dimetilssulfóxido de rutênio, entre estes $\left[\mathrm{Ru}\left(\mathrm{NH}_{3}\right)_{5} \mathrm{Cl}\right] \mathrm{Cl}_{2}(\mathbf{8 2}),\left[\mathrm{Ru}\left(\mathrm{NH}_{3}\right)_{6}\right] \mathrm{Cl}_{3}(\mathbf{8 3}),\left[\mathrm{Ru}(\mathrm{DMSO})_{4} \mathrm{Cl}_{2}\right]$ (84), $\left[\mathrm{Ru}(\mathrm{DMSO})_{2}\right.$ en] $(\mathbf{8 5})$ também foi demonstrada (Figura 15). ${ }^{55,56}$

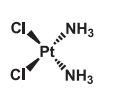

80

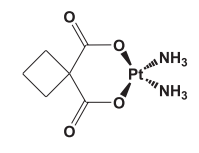

81
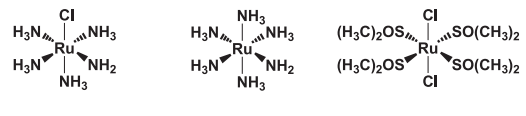

84

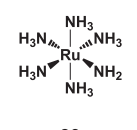

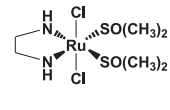

85
Figura 15. Compostos de platina e rutênio com atividade anti-T. cruzi, cisplatina (80) e carboplatina (81), $\left[\mathrm{Ru}\left(\mathrm{NH}_{3}\right)_{5} \mathrm{Cl} \mathrm{Cl}_{2}(\mathbf{8 2}),\left[\mathrm{Ru}\left(\mathrm{NH}_{3}\right)_{6}\right] \mathrm{Cl}_{3}(\mathbf{8 3})\right.$, $\left[\mathrm{Ru}(\mathrm{DMSO})_{4} \mathrm{Cl}_{2}\right](84),\left[\mathrm{Ru}(\mathrm{DMSO})_{2}\right.$ en $](85)$

A partir destas descobertas, as pesquisas evoluíram para a descoberta de novos compostos de platina e de rutênio que demonstraram propriedades interessantes de toxicidade e atividade contra o T. cruzi.$^{56}$ Compostos de metais de transição, tais como platina (II e IV), rutênio (II e III), ródio (I e II) e irídio (I e II) foram usados empiricamente contra o T. cruzi..$^{77-79}$ Há cerca de uma década foi demonstrada a atividade anti-T. cruzi de alguns compostos de ósmio (III), que atuavam em sinergia com ligantes nitro-imidazólicos, inclusive com o benzonidazol (4) (Figura 1). Estes complexos mostraram significativa inibição do crescimento de formas epimastigotas, mas foram citotóxicos contra macrófagos e células Vero. ${ }^{57}$ Foi postulado que estes compostos atuavam através da inibição das enzimas succinato desidrogenase (EC 1.3.99.1), malato desidrogenase (EC 1.1.1.37) e piruvato quinase (EC 2.7.1.40), ou pela interação com o DNA e RNA. ${ }^{57}$

Outra estratégia de desenvolvimento de complexos anti-T. cruzi foi empregada a partir da década de 90 considerando a sinergia entre metais de transição (e.g., rutênio, cobre, ferro) e inibidores da biossíntese de esteróis do T. cruzi.$^{55}$ Foi descrito que inibidores da enzima citocromo P450 14 $\alpha$-demetilase, tais como o cetoconazol (15) (Figura 4) e o clotrimazol (86) (Figura 16) eram mais ativos quando ligados a metais de transição. A partir disso, uma série de trabalhos tem demonstrado que a atividade pode ser aumentada em até 10 vezes quando estes inibidores estão coordenados ao rutênio (II/ III).$^{55}$ Os complexos de rutênio de fórmula geral $\left[\mathrm{RuCl}_{n} \mathrm{~L}\right],\left[\mathrm{Ru}\left(\mathrm{H}_{2} \mathrm{O}\right)\right.$ $\mathrm{Cl}_{\mathrm{n}} \mathrm{L}$ ] e $\left.\mathrm{Ru}(\mathrm{DMSO})_{\mathrm{n}} \mathrm{L}\right]$ (87) (Figura 16) também foram mais ativos e menos citotóxicos que os respectivos complexos de rênio, ouro, platina e cobre.$^{55}$ Estas propriedades foram atribuídas à similaridade no metabolismo entre os compostos de rutênio e ferro, a qual tem sido reivindicada como responsável pela baixa toxicidade destes compostos na quimioterapia do câncer.

Baseando-se ainda na estratégia de sinergia, mais recentemente foi sintetizado um derivado inorgânico do benzonidazol com o objetivo de melhorar a eficácia, reduzir a toxicidade e aumentar a hidrossolubilidade. ${ }^{58}$ Considerando-se que o mecanismo de ação do benzonidazol (4) envolve a redução do grupo nitro, o ancoramento deste fármaco num complexo de rutênio poderia facilitar o processo de nitrorredução e, assim, melhorar a sua potência e eficácia. De fato, o derivado de rutênio do benzonidazol, trans-[Ru(Bz) $\left.\left(\mathrm{NH}_{3}\right)_{4}\left(\mathrm{SO}_{2}\right)\right]^{2+}$ (88) (Figura 16) demonstrou potencial como candidato a fármaco anti-T. cruzi, com atividade in vivo similar, porém numa dose 1.000 vezes menor que a usada clinicamente para o benzonidazol (4).$^{58}$
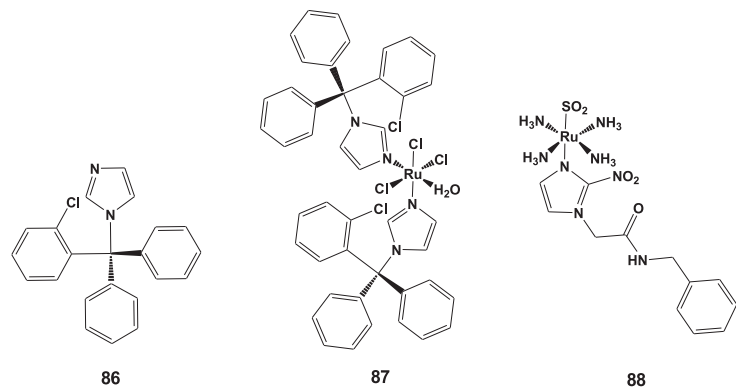

Figura 16. Complexos com atividade anti-T. cruzi, clotimazol (86), [Ru( $\left.\mathrm{H}_{2} \mathrm{O}\right)$ $\left.(\mathrm{Ctz})_{2} \mathrm{Cl}_{3}\right](87)$ e trans- $\left[\mathrm{Ru}(\mathrm{Bz})\left(\mathrm{NH}_{3}\right)_{4}\left(\mathrm{SO}_{2}\right)\right]^{2+}(88)$

\section{PADRONIZAÇÃO DE DADOS BIOLÓGICOS NAS PESQUISAS POR NOVOS FÁRMACOS}

Dentre os requerimentos estabelecidos pela OMS para bons candidatos a fármacos antichagásicos estão alta potência e seletividade contra as formas mamíferas do $T$. cruzi; eficácia em modelos experimentais agudos e crônicos da doença de Chagas; elevada biodisponibilidade em humanos; administração por via oral; uma única dose diária; tratamento em poucas doses; baixa toxicidade; segurança para administração em crianças e gestantes; princípio ativo com manufaturamento simples; e baixo custo. ${ }^{19,34}$ Para alcançar essas características é necessário passar por diversas etapas de pesquisa básica, que vão desde a identificação de moléculas bioativas até a otimização e desenvolvimento de NCEs. Uma das grandes dificuldades encontradas pelos pesquisadores na área de doença de Chagas está justamente na falta de padronização de protocolos experimentais e de cepas do T. cruzi para avaliação de substâncias com atividade antichagásica. Estima-se que existam catalogadas mais de 35 cepas do T. cruzi, as quais apresentam diferentes perfis de resistência e susceptibilidade aos fármacos padrões 3 e 4 (Figura 1). Um número também considerável de protocolos pode ser encontrado na literatura, apresentando variações importantes. Esses fatores fazem com que as análises de diferentes resultados e experimentos sejam muito difíceis, levando geralmente a informações de pouca importância prática para o desenvolvimento de um novo candidato a fármaco.

A geração de informações padronizadas de fácil acesso e análise é uma questão fundamental para que os diferentes grupos internacionais envolvidos na identificação e planejamento de moléculas bioativas possam contribuir e interagir de forma mais efetiva. Para alcançar esta meta, a OMS tem adotado em sua rede de pesquisas do programa TDR, um protocolo experimental padrão baseado em uma única cepa do T. cruzi, o que tem permitido a produção de resultados de alta qualidade que podem ser comparados pelos diferentes laboratórios acadêmicos e industriais da rede. ${ }^{32}$ Este é um aspecto de grande relevância, especialmente na área de doença negligenciadas, onde existe uma necessidade premente de ações globais capazes de promover maiores avanços das pesquisas. Neste tópico são discutidos os protocolos experimentais in vitro e in vivo usados pela OMS em seu programa de pesquisas por novos fármacos para a doença de Chagas. Estes protocolos foram adotados também no Brasil no Centro de Referência de Química Medicinal para Doença de Chagas, criado pela OMS no programa TDR e que é composto por um grupo de pesquisadores da USP e da UNICAMP (autores deste artigo de 
revisão). A estratégia de pesquisa por novos fármacos no programa TDR/OMS envolve a integração do planejamento de química medicinal com a síntese orgânica e a avaliação biológica (in vitro e in vivo). Um esquema geral para as pesquisas visando a descoberta $\mathrm{e}$ otimização de compostos líderes é apresentado na Figura 17. O desenvolvimento de candidatos a novos fármacos para o tratamento da doença de Chagas passa essencialmente pelo cumprimento das etapas apresentadas nesse esquema. Os protocolos de ensaios in vitro e in vivo executados nas diferentes etapas seguem padrões rigorosos de qualidade de experimentação, coleta, tratamento e análise de dados.

\section{Candidato}

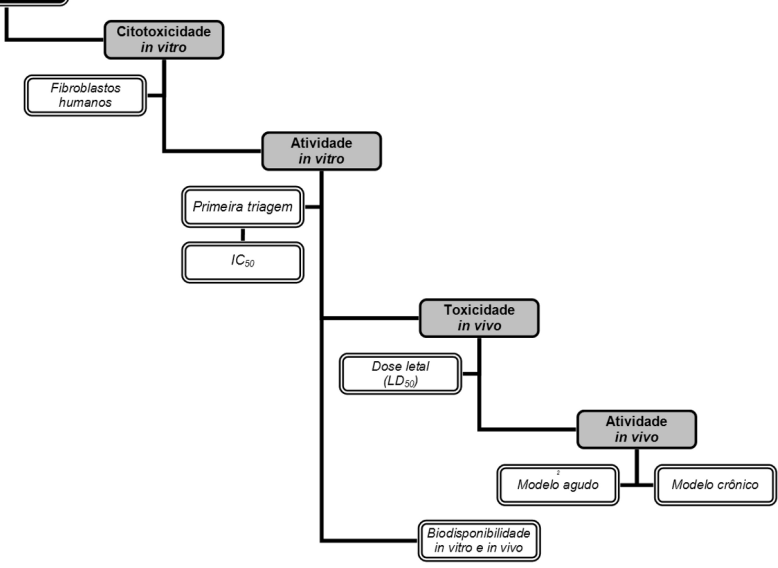

Figura 17. Estratégia integrada para a descoberta de candidatos a novos fármacos para o tratamento da doença de Chagas

O ensaio in vitro de avaliação de substâncias emprega uma cepa do T. cruzi chamada Tulahuen $L a c Z$, que expressa constitutivamente a enzima $\beta$-galactosidase ( $\beta$-Gal, EC 3.2.1.23) oriunda da bactéria Escherichia coli. ${ }^{80}$ Esta enzima é responsável pela clivagem do substrato vermelho de clorofenol $\beta$-D-galactopirano (89) (região do amarelo do espectro visível) dando origem aos produtos D-galactose (90, incolor) e vermelho de clorofenol (91, região do vermelho do espectro visível) (Figura 18). ${ }^{80}$

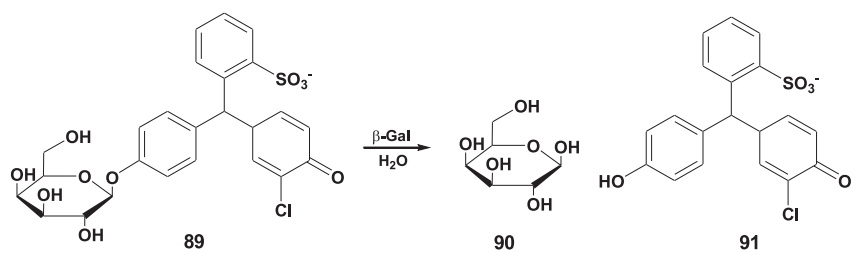

Figura 18. Esquema reacional da clivagem do substrato vermelho de clorofenol $\beta$-D-galactopirano (89) levando à formação de galactose (90) e vermelho de clorofenol (91), pela ação da enzima $\beta-G a l$

No mecanismo do ensaio, os parasitas viáveis presentes no meio reacional expressam a $\beta-G a l$, que por sua vez converte o substrato 89 nos produtos 90 e 91. Desta forma, a atividade anti-T. cruzi in vitro pode ser determinada através de reação colorimétrica pela medida direta da absorbância do produto 91 em 570 nm, que é linear com a concentração de parasitas no meio no intervalo de 500 a $1,5 \times 10^{5}$ parasitas $/ \mathrm{mL}$. Esta cepa geneticamente modificada, adotada pela OMS como padrão para os experimentos in vitro com moléculas provenientes de fontes naturais ou sintéticas, apresenta um série de vantagens. Com a Tulahuen LacZé possível fazer experimentos em uma escala de tempo 10 vezes menor em comparação com outros métodos convencionais que se baseiam na contagem de parasitas ao microscópio. ${ }^{80} \mathrm{O}$ método de análise é bastante consistente e fornece resultados muito confiáveis e reprodutíveis.

Os compostos podem também ser submetidos inicialmente a testes de toxicidade usando fibroblastos humanos, de acordo com a Figura 17. Após a determinação de valores de $\mathrm{IC}_{50}$, estes são agrupados de acordo com a Tabela 2. A utilização de agrupamentos de compostos por pontuação (1, 2 e 3 da Tabela 2) faz parte dos procedimentos padrões de coleta e análise de resultados. Somente os compostos que apresentarem pontuação 3 ( IC $_{50}{ }^{\text {fib }}>30 \mu \mathrm{M}$ ) são submetidos aos ensaios de atividade anti-T. cruzi $\left(\mathrm{IC}_{50}\right.$ ama $)$, usando-se como parâmetro as formas amastigotas.

Tabela 2. Análise de dados padrões de ensaios in vitro de toxicidade e atividade anti-T. cruzi

\begin{tabular}{lcc}
\hline Pontuação & $\begin{array}{c}\text { Toxicidade in vitro } \\
\mathrm{IC}_{50}{ }^{\text {fib }}(\mu \mathrm{M})\end{array}$ & $\begin{array}{c}\text { Atividade in vitro } \\
\mathrm{IC}_{50}{ }^{\text {ama }}(\mu \mathrm{M})\end{array}$ \\
\hline 1 & $<10$ & $>30$ \\
2 & $30<\mathrm{IC}_{50}<10$ & $30<\mathrm{IC}_{50}<10$ \\
3 & $>30$ & $<10$ \\
\hline
\end{tabular}

No ensaio de atividade anti-T. cruzi in vitro, fibroblastos humanos (HF) são semeados em placas de 96 poços e após $12 \mathrm{~h}$ são infectados com tripomastigotas metacíclicas previamente cultivadas em fibroblastos ou em células Vero (Figura 19B). Passadas 24 h da infecção, os compostos que receberam pontuação 3 na triagem de toxicidade (Tabela 2) são adicionados de acordo com o modelo ilustrado na Figura 20A, sendo que o fármaco benzonidazol (4, Figura 1) é usado como referência. Após a adição dos compostos, as placas são incubadas a $37{ }^{\circ} \mathrm{C} \mathrm{e} \pm 5 \%$ de $\mathrm{CO}_{2}$ por 5 dias. Ao final deste período, o substrato 82 é adicionado conferindo uma coloração amarela ao meio experimental como mostrado na Figura 19B (iv). Após 3 h de reincubação nas mesmas condições, a placa é analisada em espectrofotômetro a $570 \mathrm{~nm}$ (Figura 19B - v). A porcentagem de parasitas viáveis é então aferida tomando-se como controle os poços da linha A (sem a adição de compostos). Nos protocolos padrões, primeiramente, as moléculas selecionadas são submetidas aos ensaios usando três concentrações (primeira triagem) e somente aquelas que apresentarem $50 \%$ de atividade a $30 \mu \mathrm{M}$ são selecionadas para o ensaio de determinação de $\mathrm{IC}_{50}$, sendo posteriormente classificadas de acordo com a Tabela 2.

A
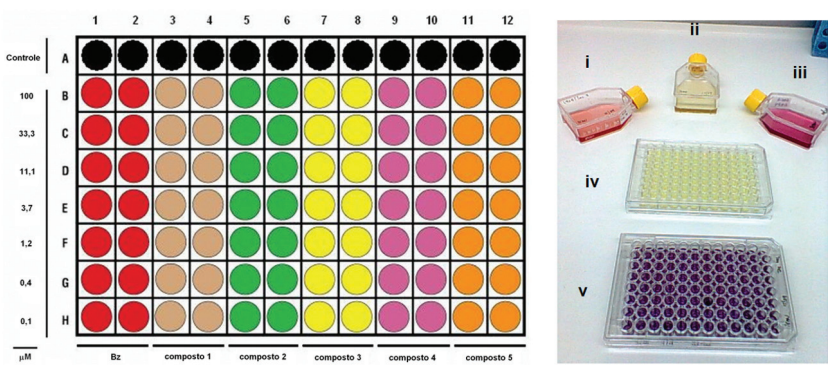

Figura 19. A. Esquema de semeamento dos candidatos a fármacos; $B$. fibroblastos humanos (i), formas epimastigotas (ii) e tripomastigotas metacíclicas (iii) usadas para a triagem de novos compostos. Representação do experimento logo após a adição do substrato (iv). Viabilidade do parasita 3 h após a adição do substrato (v)

Na fase seguinte, de acordo com o esquema geral da Figura 17, ensaios de atividade in vivo são realizados com as moléculas com pontuação 2 ou 3. Contudo, a toxicidade aguda em camundongos é avaliada para cada molécula selecionada. Para isso, um camundongo fêmea BALB/c é selecionado para a administração de doses acumulativas 
por via intraperitoneal de acordo com o esquema indicado na Tabela 3. Após cada dose administrada, são monitorados sinais de toxicidade aguda tais como sede, hiperventilação e tremores ${ }^{81}$ Se nenhum sinal for detectado, uma nova dose é administrada até que estes sinais se tornem evidentes, ou que a dose máxima de $150 \mathrm{mg} / \mathrm{kg}$ seja alcançada. Somente as moléculas com dose acumulada maior ou igual a $100 \mathrm{mg} /$ kg são selecionadas para os experimentos com animais infectados.

Tabela 3. Esquema terapêutico para determinação de toxicidade aguda

\begin{tabular}{lcc}
\hline $\begin{array}{l}\text { Tempo } \\
(\mathrm{h})\end{array}$ & $\begin{array}{c}\text { Dose aplicada } \\
(\mathrm{mg} / \mathrm{kg})\end{array}$ & $\begin{array}{c}\text { Dose acumulada } \\
(\mathrm{mg} / \mathrm{kg})\end{array}$ \\
\hline 0 & 20 & 20 \\
2 & 30 & 50 \\
4 & 50 & 100 \\
6 & 50 & 150 \\
\hline
\end{tabular}

Nos ensaios de infecção aguda, grupos de 5 ou 6 camundongos fêmeas BALB/c são infectados com a cepa Tulahuen silvestre por via intraperitoneal a uma carga parasitária média objetivando gerar um modelo de infecção aguda. No terceiro dia, os animais são verificados e somente aqueles que mostram infecção positiva são considerados para o ensaio de atividade tripanocida. Os animais são mantidos durante os experimentos sob temperatura controlada $\left(22-25^{\circ} \mathrm{C}\right)$, com água e ração ad libitum. Os compostos testados são administrados inicialmente por via intraperitoneal em diferentes esquemas terapêuticos conforme a Tabela 4 . O benzonidazol (4, Figura 1) é usado como referência (controle positivo), sendo administrado por via oral (gavagem) dissolvido em PBS contendo goma arábica. O curso da infecção é então acompanhado nos dias 3, 5, 7, 9, 11, 13, 15, 18, 21, 25 e 30 após a infecção, sempre pela contagem do número de formas tripomastigotas móveis em $5 \mu \mathrm{L}$ de sangue retirados da veia caudal. ${ }^{82}$

Tabela 4. Esquemas terapêuticos para os experimentos in vivo

\begin{tabular}{|c|c|c|}
\hline $\begin{array}{l}\text { Ensaio } \\
\text { (dose } \mathrm{mg} / \mathrm{kg} \text { ) }\end{array}$ & $\begin{array}{l}\text { Tratamento } \\
\text { (rota) }\end{array}$ & $\begin{array}{c}\text { Critério } \\
\text { de atividade }\end{array}$ \\
\hline $1(50)$ & $\begin{array}{l}10 \text { dias consecutivos a partir } \\
\text { do dia } 3 \text { após a infecção (i.p.) }\end{array}$ & $\begin{array}{c}\text { Sobrevivência maior } \\
\text { que } 30 \text { dias }\end{array}$ \\
\hline $2(50)$ & $\begin{array}{c}\text { Somente nos três dias que } \\
\text { precede o pico parasitêmico } \\
\text { (i.p.) }\end{array}$ & $\begin{array}{c}\text { Sobrevivência maior } \\
\text { que } 40 \text { dias }\end{array}$ \\
\hline $\begin{array}{l}3 \text { (dose resposta: } \\
10,30,90 \text { e } 150)\end{array}$ & $\begin{array}{l}\text { Durante } 15 \text { dias consecuti- } \\
\text { vos a partir do dia } 3 \text { após a } \\
\text { infecção (p.o.) }\end{array}$ & $\begin{array}{l}\text { Determinação de } \\
* \mathrm{ED}_{50}\end{array}$ \\
\hline
\end{tabular}

*Dose referente a $50 \%$ de sobrevida dos animais infectados por mais de 120 dias

As moléculas que apresentam valores de $\mathrm{ED}_{50} \approx 50 \mathrm{mg} / \mathrm{kg}$ têm seus valores de dose letal determinados $\left(\mathrm{LD}_{50}\right)$ usando-se protocolos alternativos que estão em acordo com os princípios dos $3 R$, de redução, reutilização e reciclagem (replacement, reduction, and refinement). Por fim, as moléculas que apresentarem a relação $\mathrm{LD}_{50} / 100 \approx 10$ são testadas usando-se um modelo crônico de infecção experimental, com administração por via oral.

\section{PROGRAMAS GLOBAIS ESPECIAIS DE PESQUISA EM DOENÇAS NEGLIGENCIADAS}

Os avanços das ciências biológicas e químicas nos últimos 100 anos impulsionaram a descoberta de novos fármacos com ações terapêuticas extraordinárias, proporcionando melhorias na qualidade de vida de milhões de pessoas no mundo. Em contraste com as várias áreas terapêuticas importantes que têm sido beneficiadas de forma notável pelos avanços da indústria farmacêutica, as doenças negligenciadas carecem de mais programas de $\mathrm{P} \& \mathrm{D}$ de fármacos. Ações globais especiais, capazes de integrar elementos essenciais de pesquisa, desenvolvimento, inovação e organização, são extremamente importantes neste contexto. São vários os programas internacionais que poderiam ser citados como exemplo, mas apenas dois casos serão destacados nesta revisão.

\section{Programa especial para pesquisa e treinamento em doenças tropicais (TDR)}

O TDR é uma ação global de colaboração científica que tem o papel de criar, apoiar, integrar e coordenar esforços globais com o objetivo de diminuir o impacto econômico e social das doenças negligenciadas. Fundado em 1975, o TDR é patrocinado por um grupo formado pelo Fundo Infantil das Nações Unidas (UNICEF - The United Nations Children's Fund), Nações Unidas para o Desenvolvimento (UNDP - United Nations Development Programme), Banco Mundial (The World Bank) e OMS. As ações coordenadas pelo TDR em seu programa de descoberta de candidatos a fármacos para doenças tropicais infecciosas (lead discovery for drugs for infectious tropical diseases) têm se mostrado muito promissoras e capazes de promover cooperações efetivas entre pesquisadores de universidades e indústrias farmacêuticas de diversos países. Este programa especial, do qual o Brasil faz parte, envolve as redes de triagem de compostos (compound screening network), de identificação de alvos (drug target network), de farmacocinética e metabolismo de fármacos (drug metabolism and pharmacokinetics network), e de química medicinal (medicinal chemistry network). Um modelo geral de estratégia de pesquisa básica do programa de descoberta de candidatos a fármacos para doenças negligenciadas do TDR é ilustrado na Figura 20., ${ }^{2,32}$

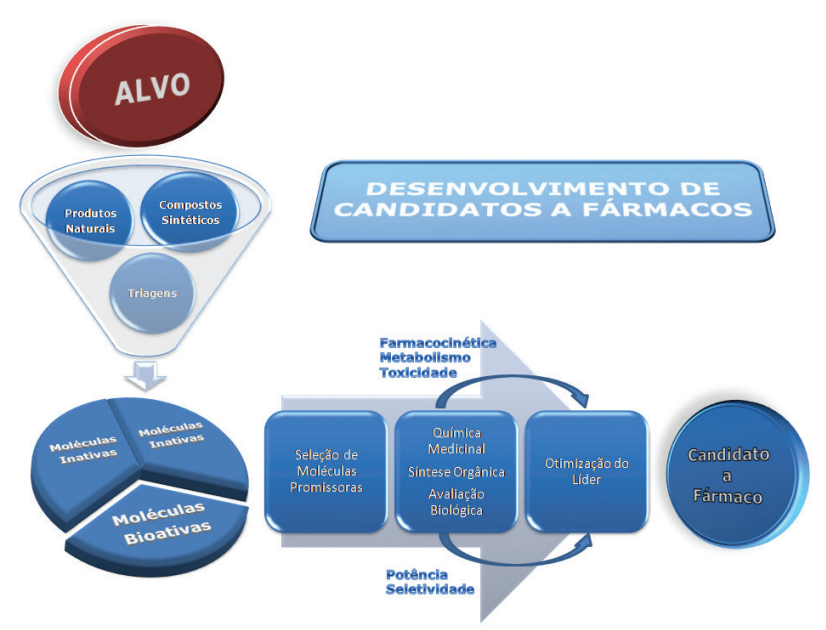

Figura 20. Estratégias do TDR para a descoberta de compostos bioativos candidatos a novos fármacos contra as doenças negligenciadas

Neste modelo, a identificação de novas moléculas bioativas ou ligantes (hit) se dá através das redes especiais de triagem in vitro de compostos contra alvos específicos validados, como enzimas, ou diretamente em cultura de parasitas. As moléculas bioativas mais promissoras são selecionadas para uma fase posterior de otimização, que engloba o planejamento em química medicinal, a síntese e a avaliação biológica in vitro e in vivo de novos compostos, além de estudos de toxicidade básica e de propriedades farmacocinéticas (e.g., 
absorção, biodisponibilidade). O emprego de controles negativos e positivos, e o monitoramento constante em relação aos fármacos e outras moléculas bioativas de referência são componentes importantes no processo de padronização e validação de resultados. O objetivo final é a descoberta e otimização de compostos líderes com propriedades farmacodinâmicas e farmacocinéticas qualificadas, capazes de representarem NCEs. Dessa forma, torna-se possível uma avaliação rigorosa do potencial de desenvolvimento clínico (triagens clínicas em humanos) dos novos candidatos a fármacos, pois os mesmos tiveram suas propriedades de atividade, toxicidade e biodisponibilidade determinadas em modelos padrões in vitro e in vivo.

Na rede de descoberta de candidatos a fármacos antiparasitários coordenada pelo TDR, as contribuições da universidade e da indústria farmacêutica têm sido essenciais para o progresso das pesquisas na identificação de vários candidatos a novos fármacos, sendo esta integração indispensável para o sucesso do programa. ${ }^{31,83,84}$ Para se ter uma melhor ideia da equipe internacional que atua neste programa, podemos citar os parceiros acadêmicos e industriais que fazem parte da rede de química medicinal: Pfizer (Reino Unido), Merck Serono (Suíça), Chemtura (Canadá), Pharmacopeia (EUA), Universidade de Cape Town (África do Sul), St. Jude Children's Research Hospital (EUA), Universidade de Nebraska (EUA), Universidade de Dundee (Reino Unido), Universidade Estadual de Ohio (EUA), Universidade de São Paulo/UNICAMP (Brasil). O papel da universidade ganha destaque na geração de conhecimento e na aplicação de ferramentas e métodos para o desenvolvimento de diversas etapas básicas fundamentais, incorporando a validação de alvos biológicos, as triagens experimentais in vitro e in vivo, o planejamento e síntese de novos compostos, bem como os estudos de farmacocinética e metabolismo. Em contrapartida, a contribuição da indústria farmacêutica pode ser notada no desenvolvimento de triagens biológicas automatizadas em larga escala (HTS - high-throughput screening), nos estudos pré-clínicos e clínicos, no suporte gerencial e no acompanhamento dos projetos, além de importante participação no financiamento de projetos. Vale ressaltar que algumas organizações filantrópicas, como as Fundações americanas Bill \& Melinda Gattes e Rockefeller e a Fundação britânica Wellcome Trust, têm sua contribuição através do financiamento de projetos com objetivos e metas bem estabelecidos.

\section{Iniciativa de medicamentos para doenças negligenciadas (DNDi)}

Desde 1971, a organização internacional de ajuda humanitária Médicos Sem Fronteiras vem testemunhando, por meio de seus projetos espalhados em mais de 70 países do mundo, como a falta de tratamentos eficazes e acessíveis para as doenças negligenciadas afeta a humanidade de forma impiedosa, desproporcional e injusta. Profissionais de saúde desta organização perceberam que o processo de desenvolvimento de medicamentos para as doenças tropicais estava praticamente estagnado. Para se ter uma dimensão do problema, nos últimos 25 anos, apenas $1 \%$ de todos os medicamentos desenvolvidos foi para tratar alguma doença negligenciada. ${ }^{85}$ $\mathrm{Na}$ ausência de novas alternativas terapêuticas para doenças cada vez mais graves, os médicos se veem ainda obrigados a recorrer a medicamentos e tratamentos antigos, que se tornam cada vez mais ineficazes. Em função disso, a organização Médicos Sem Fronteiras decidiu destinar a quantia recebida pelo seu prêmio Nobel da Paz ao estudo das necessidades médicas dos pacientes que sofrem dessas doenças, resultando em julho de 2003 na criação da Iniciativa de Medicamentos para Doenças Negligenciadas (DNDi - Drugs for Neglected Diseases initiative), fruto da união de 7 organizações espalhadas pelos cinco continentes. ${ }^{86,87}$ Os parceiros fundadores da DNDi são formados por quatro instituições públicas de pesquisa médica de países em desenvolvimento, uma instituição privada de pesquisa, uma organização internacional de pesquisa e uma organização internacional de ajuda humanitária da área de saúde. São, respectivamente: Fundação Oswaldo Cruz (FIOCRUZ, Brasil), Conselho Indiano de Pesquisa Médica, Ministério da Saúde da Malásia, Instituto de Pesquisa Médica do Quênia, Instituto Pasteur (França), PNUD/Banco Mundial/TDR/OMS) e Médicos Sem Fronteiras (MSF).

A missão principal da DNDi é pesquisar e desenvolver medicamentos eficazes, adaptados e financeiramente acessíveis para o tratamento das doenças negligenciadas, preenchendo as lacunas que existem em P\&D de medicamentos para essas doenças. A DNDi cria e coordena projetos em $\mathrm{P} \& \mathrm{D}$ de fármacos para doenças negligenciadas em parceria com a comunidade internacional de pesquisa, o setor público, a indústria farmacêutica, além de outros parceiros. Dentre suas atividades relevantes na área de doença de Chagas, destacam-se (i) o consórcio para a otimização de compostos líderes, que se destina ao desenvolvimento de moléculas da fase inicial de triagens. Os principais parceiros são o Centro para Otimização de Candidatos a Fármacos (CDCO - The Centre for Drug Candidate Optimisation, da Austrália), Epichem (Austrália), Universidade de Murdoch (Austrália) e a Universidade Federal de Ouro Preto (Brasil); (ii) identificação de compostos azólicos, que se preocupa com a avaliação da nova geração de antifúngicos azólicos, com a finalidade de selecionar novos candidatos para desenvolvimento pré-clínico e clínico visando o tratamento da doença de Chagas; (iii) benzonidazol pediátrico, que visa o desenvolvimento de uma formulação de benzonidazol para crianças em parceria com o Laboratório Farmacêutico do Estado de Pernambuco (LAFEPE). A DNDi atua também em outros programas envolvendo doenças como a malária, triapanossomíase africana e leishmaniose.

\section{CONCLUSÕES E PERSPECTIVAS}

Chegamos ao primeiro centenário da descoberta da doença de Chagas sem qualquer fármaco seguro e eficaz que pudesse coroar de êxito o feito extraordinário realizado por Carlos Chagas. A fase crônica da doença permanece sem alternativas de tratamento, representando grave problema que tem elevado o sofrimento de milhões de infectados na América Latina. Iniciativas de arquitetura complexa como a do TDR e da DNDi, entre outras, representam grande esperança para o desenvolvimento de um novo medicamento. Contudo, novos programas de pesquisas, capazes de integrar redes internacionais de trabalho envolvendo pesquisadores de instituições do setor público e do setor privado, são necessários e devem ser incentivados, principalmente nos países em desenvolvimento. A tríade Universidade - Governo - Empresa é um caminho que deve ser seguido no estabelecimento de parcerias efetivas. O Brasil, bem como outros países que sofrem com as doenças negligenciadas, possui recursos humanos qualificados, centros de pesquisa e agências de fomento capazes de associar as estratégias de organização e pesquisa para enfrentar com criatividade estes desafios de todas as perspectivas. Os resultados destas iniciativas seriam percebidos no fortalecimento da política científica e tecnológica do país, no desenvolvimento da ciência e educação, na formação contínua de recursos humanos qualificados e, sobretudo, na sua benfeitoria mais nobre, no melhoramento das condições de saúde pública e bem-estar social de milhões de pessoas que vivem em condições desumanas nas áreas mais atingidas pelas doenças parasitárias. Os autores desta revisão celebram os 100 anos da descoberta de doença de Chagas, colocando como perspectiva para o próximo centenário o desenvolvimento de novos fármacos e vacinas para a doença de Chagas, bem como para outras doenças negligenciadas. Espera-se que as novas gerações de cientistas brasileiros possam contribuir efetivamente nesse processo, da forma louvável como tem sido feito pela geração atual e por aque- 
las passadas. Para o ano de 2109 , coloca-se como desafio às novas gerações de pesquisadores que nos sucederão o preparo de um artigo de revisão dos 200 anos da descoberta da doença de Chagas, onde poderão, felizmente, ao lembrar desse artigo, descrever as histórias de sucesso do desenvolvimento de fármacos ou vacinas que foram fundamentais para o controle e tratamento da doença de Chagas.

\section{AGRADECIMENTOS}

À OMS (Organização Mundial de Saúde), FAPESP (Fundação de Amparo à Pesquisa do Estado de São Paulo) e CNPq (Conselho Nacional de Desenvolvimento Científico e Tecnológico) pelo apoio científico e financeiro às pesquisas do grupo na área de doenças negligenciadas, e ao Dr. R. V. C. Guido (Universidade de São Paulo) pelas valiosas discussões e sugestões.

\section{REFERÊNCIAS}

1. Ketter, H.; Marjanovic, S.; Nature Rev. Drug Discov. 2004, 3, 171.

2. Nwaka, S.; Ridley, R. G.; Nature Rev. Drug Discov. 2003, 2, 919.

3. Engels, D.; Savioli, L.; Trends Parasitol. 2006, 22, 363.

4. Gelb, M. H.; Hol, W. G.; Science 2002, 297, 343.

5. Hoare, C. A.; The trypanosomes of mammals, Blackwell Scientific Publications: Oxford, 1972, p. 20.

6. Hoare, C. A.; Wallace, F. G.; Nature 1966, 212, 1385.

7. Boainain, E.; Rassi, A.; Arq. Bras. Cardiol. 1979, 32, 395.

8. Dias, J. C.; Cad. Saúde Pub. Minist. Saúde, Fundação Oswaldo Cruz, Escola Nacional de Saúde Pública 1993, 9, 201.

9. Marin-Neto, J. A.; Simões, M. V.; Maciel, B. C. Em Uptodate In Cardiovascular Medicine, A CD-Rom Textbook. Section: Cardiomyopathies; Rose, B. D.; Podrid, P. J.; Gersh, B. J., orgs.; $1^{\text {st }}$ ed.; Wellesley: Ma, USA, 1998, vol. 6, p. 6.

10. Rossi, M. A.; Int. J. Cardiol. 1991, 30, 335.

11. Kalil, J.; Cunha-Neto, E.; Parasitol. Today 1996, 12, 396.

12. Bellotti, G.; Bocchi, E. A.; De Moraes, A. V.; Higuchi, M. L.; BarberoMarcial, M.; Sosa, E.; Am. Heart J. 1996, 131, 301.

13. Levin, M. J.; Parasitol. Today 1996, 12, 415.

14. Hayes, R.; Schofield, C. J.; Volví. Oficial Sanit. Panam. 1990, 108, 308.

15. WHO; World Health Organization Tech. Rep. Ser. 1991, 811, 1.

16. Dias, J. C.; Parasitol. Today 1995, 3, 336.

17. Brener, Z.; Andrade, Z.; Trypanosoma cruzi e Doença de Chagas, Guanabara Koogan: Rio de Janeiro, 1979, p. 362.

18. Brener, Z. Em Terapêutica experimental da doença de Chagas; Cançado, J. R., ed.; Imprensa Oficial de Minas Gerais: Belo Horizonte, 1968 , p. 510.

19. Coura, J. R.; Castro, S. L.; Mem. Inst. Oswaldo Cruz 2002, 97, 3.

20. De Castro, S. L.; Acta Tropical 1993, 53, 83.

21. Brener, Z.; Rev. Inst. Med. Trop. São Paulo 1961, 3, 43.

22. Cançado, J. R.; Marra, U. D.; Brener, Z.; Rev. Inst. Med. Trop. São Paulo 1964, 6, 12; Packchanian, A.; J. Parasitol. 1952, 38, 30; Packchanian, A.; Antib. Chemother. 1957, 7, 13; Rassi, A.; Ferreira, H. O.; Rev. Inst. Med. Trop. São Paulo 1971, 5, 235; Coura, J. R.; Ferreira, L. F.; Silva, J. R.; O Hospital 1962, 62, 957; Ferreira, H. O.; Rev. Inst. Med. Trop. São Paulo 1961, 3, 287.

23. Coura, J. R.; Castro, S. L.; Mem. Inst. Oswaldo Cruz 2002, 97, 3.

24. Rubio, M.; Donoso, F.; Bol. Chil. Parasitol. 1969, 24, 43.

25. Schenone, H.; Concha, L.; Aranda, R.; Rojas, A.; Alfaro, E.; Knierin, E.; Rojo, M.; Bol. Chil. Parasitol. 1975, 30, 91.

26. Schenone, H.; Concha, L.; Aranda, R.; Rojas, A.; Knierim, F.; Rojo, M.; Bol. Chil. Parasitol. 1972, 27, 11 .

27. Maya, J. D.; Bollo, S.; Nuñez-Vergara, L. J.; Squella, J. A.; Repetto, Y.; Morello, A.; Périé, J.; Chauvière, G.; Biochem. Pharmacol. 2003, 65, 999; Maya, J. D.; Cassels, B. K.; Iturriaga-Vásquez, P.; Ferreira,
J.; Faúdez, M.; Galanti, N.; Ferreira, A.; Morello, A.; Comp. Biochem. Physiol. A Mol. Integr. Physiol. 2007, 146, 601; Moreno, S. N.; Docampo, R.; Mason, R. P.; León, W.; Stoppani, A. O.; Archiv. Biochem Biophys. 1982, 218, 585; Mason, R. P.; Holtzman, J. L.; Biochem. Biophys. Res. Commun. 1975, 67, 1267; Temperton, N. J.; Wilkinson, S. R.; Meyer, D. J.; Kelly, J. M.; Mol. Biochem. Parasitol. 1998, 96, 167; Docampo, R.; Moreno, S. N.; Rev. Infec. Diseases 1984, 6, 223; Docampo, R.; Moreno, S. N.; Stoppani, A. O.; León, W.; Cruz, F. S.; Villalta, F.; Muñiz, R. F.; Biochem. Pharmacol. 1981, 30, 1947.

28. Díaz De Toranzo, E. G.; Castro, J. A.; Franke De Cazzulo, B. M.; Cazzulo, J. J.; Experientia 1988, 44, 880.

29. Romanha, A. J.; Alves, R. O.; Murta, S. M.; Silva, J. S.; Ropert, C.; Gazzinelli, R. T.; J. Infec. Diseases 2002, 186, 823.

30. Turrens, J. F.; Watts Jr., B. P.; Zhong, L.; Docampo, R.; Mol. Biochem. Parasitol. 1996, 82, 125.

31. Castro, J. A.; Meca, M. M.; Bartel, L. C.; Hum. Exp. Toxicol. 2006, 25, 471.

32. Nwaka, S.; Hudson, A.; Nature Rev. 2006, 5, 941.

33. Kola, I.; Mol. Therapy 2008, 83, 227.

34. Duschak, V. G.; Couto, A. S.; Recent Pat. Anti-Infec Drug Discov. 2007, 2, 19. McKerrow, J. H.; Rosenthal, P. J.; Swenerton, R.; Doyle, P.; Cur. Opin. Infc. Dis. 2008, 21, 668; Andricopulo, A. D.; Yunes, R. A.; Nunes, R. J.; Savi, A. O. S.; Cruz, A. B.; Cechinel, V.; Quim. Nova 1998, 21, 573; Sealey-Cardona, M.; Cammerer, S.; Jones, S.; Ruiz-Perez, L. M.; Brun, R.; Gilbert, I. H.; Urbina, J. A.; Gonzalez-Pacanowska, D.; Antimicrob. Agents Chemother. 2007, 51, 2123.

35. Junior, W. F. A.; Soares, M. B. P.; Cur. Drug Targets 2009, $10,193$.

36. Moreira, D. R. M.; Leite, A. C. L.; dos Santos, R. R.; Soares, M. B. P.; Cur. Drug Targets 2009, 10, 212.

37. Soeiro, M. N. C.; Castro, S. L.; Expert. Opinion 2009, 13, 105.

38. Sajid, M.; McKerrow, J. H.; Mol. Biochem. Parasitol. 2002, $120,1$.

39. Brak, K.; Doyle, P. S.; McKerrow, J. H.; Ellman, J. A.; J. Am. Chem. Soc. 2008, 130, 6404.

40. Zanatta, N.; Amaral, S. S.; dos Santos, J. M.; de Mello, D. L.; Fernandes, L. S.; Bonacorso, H. G.; Martins, M. A. P.; Andricopulo, A. D.; Borchhardt, D. M.; Biorg. Med. Chem. 2008, 16, 10236.

41. Fricker, S. P.; Mosi, R. M.; Cameron, B. R.; Baird, I.; Zhu, Y.; Anastassov, V.; Cox, J.; Doyle, P. S.; Hansell, E.; Lau, G.; Langille, J.; Olsen, O.; Qin, L.; Skerlj, R.; Wong, R. S. Y.; Santucci, Z.; McKerrow, J. H.; J. Inorg. Biochem. 2008, 102, 1839.

42. Ascenzi, P.; Salvati, L.; Bolognesi, M.; Colasanti, M.; Polticelli, F.; Venturini, G.; Curr. Prot. Pept. Sci. 2001, 2, 137.

43. Silva, J. J. N.; Osakabe, A. L.; Pavanelli, W. R.; Silva, J. S.; Franco, D. W.; Br. J. Pharmacol. 2007, 152, 112.

44. Doyle, P.; Zhou, Y. M.; Engel, J. C.; McKerrow, J. H.; Antimicrob. Agents Chemother. 2007, 51, 3932.

45. Apt, W.; Aguilera, X.; Arribada, A.; Perez, C.; Miranda, C.; Sanchez, G.; Zulantay, I.; Cortes, P.; Rodriguez, J.; Júri, D.; Am. J. Trop. Med. Hyg. 1998, 59, 133.

46. Hucke, O.; Gelb, M. H.; Verlinde, C. L.; Buckner, F. S.; J. Med. Chem. $\mathbf{2 0 0 5}, 48,5415$.

47. Kraus, J. M.;Verlinde, C. L.; Karimi, M.; Lepesheva, G. I.; Gelb, M. H.; Buckner F. S.; J. Med. Chem. 2009, 52, 1639.

48. Verline, C. L. M. J.; Hannaert, V.; Blonski, C.; Willson, M.; Périé, J. J.; Fathergill-Gilmore, L. A.; Opperdoes, F. R.; Gelb, M. H.; Hol, W. G. J.; Michels, P. A. M.; Antimicrob. Anticancer Chemother. 2001, 4, 1.

49. Souza, D. H. F.; Garratt, R. C.; Araújo, A. P. U.; Guimarães, B. G.; Jesus, W. D. P.; Michels, P. A. M.; Hannaert, V.; Oliva, G.; FEBS Lett. 1998, $424,131$.

50. Urbina, J. A.; Crespo, A.; Mol. Biochem. Parasitol. 1984, 11, 225.

51. Leitao, A.; Andricopulo, A. D.; Oliva, G.; Pupo, M. T.; Marchi, A. A.; Vieira, P. C.; Silva, M. F. G. F.; Ferreira, V. F.; Sa, M. M.; Montanari, C. A.; Bioorg. Med. Chem Lett. 2004, 14, 2199. 
52. Freitas, R. F.; Prokopczyk, I. M.; Zottis, A.; Oliva, G.; Andricopulo, A D.; Trevisan, M. T. S.; Villegas, W.; Silva, M. G. V.; Montanari, C. A.; Bioorg. Med. Chem. 2009, 17, 2476.

53. Pereira, J. M.; Severino, R. P.; Vieira, P. C.; Fernandes, J. B.; Silva, M. F. G. F.; Zottis, A.; Andricopulo, A. D.; Oliva, G.; Correa, A. G.; Bioorg. Med. Chem. 2008, 16, 8889 .

54. Mohr, S.; Stamler, J. S.; Brüne, B.; FEBS Lett. 1994, 348, 223.

55. Lopez, B. E.; Wink, D. A.; Fukuto, J. M.; Arch. Biochem. Biophys. 2007, $465,430$.

56. Silva, J. J. N.; Guedes, P. M. M.; Zottis, A.; Balliano, T. L.; da Silva, F. O. N.; Lopes, L. G. F.; Ellena, J.; Oliva, G.; Silva, J. S.; Andricopulo, A. D.; Franco, D. W.; Br. J. Pharmacol. 2009, in press.

57. Wilkinson, S. R.; Kelly, J. M. Em Molecular Mechanisms in the Pathogenesis of Chagas' Disease; Kelly, J. M., ed.; Landes Bioscience: London 2003, p. 56.

58. Silva, J. J. N.; Pavanelli, W. R.; Gutierrez, F. R. S.; Lima, F. C. A.; Silva, A. B. F.; Silva, J. S.; Franco, D. W.; J. Med. Chem. 2008, 51, 4104.

59. Gutteridge, J. M.; Halliwell, B.; Ann. New York Acad. Sci. 2000, 899, 136.

60. Lopez, J. A.; Carvalho, T. U.; de Souza, W.; Flohe, L.; Guerrero, S. A.; Montemartini, M.; Kalisz, H. M.; Nogoceke, E.; Singh, M.; Alves, M. J. M.; Colli, W.; Free Radic. Biol. Med. 2000, $28,767$.

61. Frasch, A. C. C.; Leguizamon, M. S.; Campetella, O.; Russomando, G.; J. Infect. Dis. 1994, 170, 1570.

62. Tse-Dinh, Y. C.; Infect. Disord. Drug Targets 2007, 7, 3.

63. Guido, R. V. C.; Oliva, G.; Andricopulo, A. D.; Cur. Med. Chem. 2008, 15,37 .

64. Andricopulo, A. D.; Montanari, C. A.; Mini-Rev. Med. Chem. 2005, 5, 585.

65. Andricopulo, A. D.; Akoachere, M. B.; Krogh, R.; Nickel, C.; Mcleish, M. J.; Kenyon, G. L.; Arscott, L. D.; Williams, C. H.; Davioud-Chavert, E.; Becker, K.; Bioorg. Med. Chem. Lett. 2006, 16, 2283.

66. Chung, M. C.; Guido, R. V. C.; Martinelli, T. F.; Goncalves, M. F.; Polli, M. C.; Botelho, K. C. A.; Varanda, E. A.; Colli, W.; Miranda, M. T. M.; Ferreira, E. I.; Bioorg. Med. Chem. 2003, 11, 4779.

67. Cerecetto, H.; Di Maio, R.; González, M.; Risso, M.; Saenz, P.; Seoane, G.; Denicola, A.; Peluffo, G.; Quijano, C.; Olea-Azar, C.; J. Med. Chem. 1999, 42, 1941; Aguirre, G.; Cerecetto, H.; Di Maio, R.; Gonza'lez, M.; Porcal, W.;Seoane, G.; Denicola, A.; Ortega, M. A.; Aldana, I.; MongeVega, A.; Arch. Pharm. 2002, 335, 15; Olea-Azar, C.; Rigol, C.; Opazo, L.; Morello, A.; Maya, J. D.; Repetto, Y.; Aguirre, G.; Cerecetto, H.; Di Maio, R.; González, M.; Porcal, W.; J. Chil. Chem. Soc. 2003, 48, 77; Olea-Azar, C.; Rigol, C.; Mendizábal, F.; Briones, R.; Cerecetto, H.; Di Maio, R.; González, M.; Porcal, W.; Risso, M.; Spectrochim. Acta Part A
2003, 59, 69; Olea-Azar, C.; Rigol, C.; Mendizábal, F.; Cerecetto, H.; Di Maio, R.; González, M.; Porcal, W.; Morello, A.; Repetto, Y.; Maya, J. D.; Lett. Drug Des. Discov. 2005, 2, 294.; Aguirre, G.; Boiani, L.; Boiani, M.; Cerecetto, H.; Di Maio, R.; González, M.; Porcal, W.; Denicola, A.; Piro, O. E.; Castellano, E. E.; Sant'Anna, C. M. R.; Barreiro, E. J.; Bioorg. Med. Chem. 2005, 13, 6336.

68. Aguirre, G.; Boiani, L.; Cerecetto, H.; Di Maio, R.; González, M.; Porcal, W.; Thomson, L.; Tórtora, V.; Denicola, A.; Moller, M.; Bioorg. Med. Chem. 2005, 13, 6324.

69. Aguirre, G.; Boiani, M.; Cerecetto, H.; Gerpe, A.; González, M.; Fernández S.; Denicola, A.; Ochoa de Ocáriz, C.; Nogal, J. J.; Montero, D.; Escario, J. A.; Arch. Pharm. 2004, 337, 259.

70. Boiani, M.; González, M.; Mini-Rev. Med. Chem. 2005, 5, 235.

71. Fielden, R.; Meth-Cohn, O.; Price, D.; Suschitzky, H.; J. Chem. Soc., Perkin Trans. 1973, 1, 696.

72. Baliani, A.; Bueno, G. J.; Stewart, M. L.; Yardley, V.; Brun, R.; Barrett, M. P.; Gilbert, I. H.; J. Med. Chem. 2005, 48, 5570

73. Carter, N. S.; Fairlamb, A. H.; Nature 1993, 361, 173.

74. Stewart, M. L.; Bueno, G. J.; Baliani, A.; Klenke, B.; Brun, R; Brock, J. M.; Gilbert, I. H.;Barrett, M. P.; Antimicrob. Agents Chemother. 2004, 48, 1733.

75. Tye, C.-K; Kasinathan, G.; Barrett, M. P.; Brun, R.; Doyle, V. E.; Fairlamb, A. H.; Weaver, R.; Gilbert, I. H.; Bioorg. Med. Chem. 1998, 8, 811.

76. Barrett, M. P.; Fairlamb, A. H.; Parasitol. Today 1999, 15, 136.

77. Sanchez-Delgado, R. A.; Anzellotti, A.; Mini.-Rev. Med. Chem. 2004, 4, 23.

78. Otero, L.; Vieites, M.; Bioani, L.; Denicola, A.; Rigol, C.; Opazo, L.; Olea-Azar, C.; Maya, J. D.; Morello, A.; Krauth-Siegel, R. L.; Piro, O. E.; Castellano, E.; González, M.; Gambino, D.; Cerecetto, H.; J. Med. Chem. 2006, 49, 3322.

79. Sanchez-Delgado, R. A.; Navarro, M.; Lazardi, K.; Atencio, R.; Capparelli, M.; Vargas, F.; Urbina, J. A.; Bouillez, A.; Noels, A. F.; Mais, D.; Inorg. Chim. Acta 1998, 276, 528.

80. Buckner, F. S.; Verlinde, C. L. M. J.; La Flamme, A. C.; Van Voorhis, W. C.; Antimicrob. Agents Chemother. 1996, 40, 2592.

81. Bruce, R. D.; Fund. Appl. Toxicol. 1985, 5, 151.

82. Brener, Z.; Rev. Inst. Med. Trop. 1962, 4, 389.

83. http://apps.who.int/tdr/svc/research/lead-discovery-drugs, acessada em Maio 2009

84. http://apps.who.int/tdr/svc/research/lead-discovery-drugs/partnershipsnetworks, acessada em Maio 2009

85. Chirac, P.; Torreele, R.; Lancet 2006, 12, 1560

86. http://www.dndi.org, acessada em Maio 2009.

87. http://www.dndi.org.br/Portugues/sobre_dndi.aspx, acessada em Maio 2009. 